\title{
Generalized Anxiety Disorder (GAD) and Comorbid Major Depression with GAD Are Characterized by Enhanced Nitro-oxidative Stress, Increased Lipid Peroxidation, and Lowered Lipid-Associated Antioxidant Defenses
}

\author{
Michael Maes ${ }^{1,2,3,4}$ (D) Kamila Landucci Bonifacio ${ }^{1}$ - Nayara Rampazzo Morelli ${ }^{1}$ • Heber Odebrecht Vargas ${ }^{1}$. \\ Estefânia Gastaldello Moreira ${ }^{1}$ • Drozdstoy St. Stoyanov ${ }^{3}$ • Décio Sabbatini Barbosa ${ }^{1}$ • André F. Carvalho ${ }^{5,6}$. \\ Sandra Odebrecht Vargas Nunes ${ }^{1}$
}

Received: 11 February 2018 / Revised: 30 March 2018 / Accepted: 13 April 2018

(C) Springer Science+Business Media, LLC, part of Springer Nature 2018

\begin{abstract}
Accumulating evidence shows that nitro-oxidative pathways play an important role in the pathophysiology of major depressive disorder (MDD) and bipolar disorder (BD) and maybe anxiety disorders. The current study aims to examine superoxide dismutase (SOD1), catalase, lipid hydroperoxides ( $\mathrm{LOOH}$ ), nitric oxide metabolites (NOx), advanced oxidation protein products (AOPP), malondialdehyde (MDA), glutathione (GSH), paraoxonase 1 (PON1), high-density lipoprotein cholesterol (HDL), and uric acid (UA) in participants with and without generalized anxiety disorder (GAD) co-occurring or not with BD, MDD, or tobacco use disorder. $Z$ unit-weighted composite scores were computed as indices of nitro-oxidative stress driving lipid and protein oxidation. SOD1, LOOH, NOx, and uric acid were significantly higher and HDL and PON1 significantly lower in participants with GAD than in those without GAD. GAD was more adequately predicted by increased $\mathrm{SOD}+\mathrm{LOOH}+\mathrm{NOx}$ and lowered HDL + PON1 composite scores. Composite scores of nitro-oxidative stress coupled with aldehyde and AOPP production were significantly increased in participants with comorbid GAD + MDD as compared with all other study groups, namely MDD, GAD + BD, BD, GAD, and healthy controls. In conclusion, GAD is characterized by increased nitro-oxidative stress and lipid peroxidation and lowered lipid-associated antioxidant defenses, while increased uric acid levels in GAD may protect against aldehyde production and protein oxidation. This study suggests that increased nitro-oxidative stress and especially increased SOD1 activity, NO production, and lipid peroxidation as well as lowered HDL-cholesterol and PON1 activity could be novel drug targets for GAD especially when comorbid with MDD.
\end{abstract}

Michael Maes

dr.michaelmaes@hotmail.com

https://scholar.google.com.br/

citations? user=1 wzMZ7UAAAAJ\&hl=pt-BR\&oi=ao

Kamila Landucci Bonifacio

kamilalondrina@hotmail.com

Nayara Rampazzo Morelli

nayara.rampazzo@gmail.com

Heber Odebrecht Vargas

hebervargas@sercomtel.com.br

Estefânia Gastaldello Moreira

egmoreira22@hotmail.com

Drozdstoy St. Stoyanov stojanovpisevski@gmail.com

Décio Sabbatini Barbosa sabbatini2011@hotmail.com
André F. Carvalho

andrefc7@hotmail.com

Sandra Odebrecht Vargas Nunes sandranunes@sercomtel.com.br

1 Health Sciences Graduation Program, Health Sciences Center, State University of Londrina, Londrina, Parana, Brazil

2 Department of Psychiatry, Faculty of Medicine, Chulalongkorn University, Bangkok, Thailand

3 Department of Psychiatry, Medical University of Plovdiv and Technological Center for Emergency Medicine, Plovdiv, Bulgaria

4 School of Medicine, IMPACT Strategic Research Centre, Deakin University, PO Box 281, Geelong, VIC 3220, Australia

5 Department of Psychiatry, University of Toronto, Toronto, ON, Canada

6 Centre for Addiction \& Mental Health, Toronto, ON, Canada 
Keywords Generalized anxiety disorder · Major depressive disorder · Bipolar disorder · Oxidative and nitrosative stress $\cdot$ Immune $\cdot$ Inflammation

\section{Introduction}

There is evidence that activated nitro-oxidative stress pathways may participate in anxiety and anxiety disorders (Hassan et al. 2014; Bulut et al. 2013). Animal models of anxiety are accompanied by multiple indices of nitrooxidative stress including elevated generation of reactive oxygen radicals (ROS) and nitrogen species (RNS), including nitric oxide (NO) production; increased lipid peroxidation with formation of aldehydes, such as malondialdehyde (MDA); and lowered antioxidant enzymes including catalase and glutathione peroxidase (GPx) (Rammal et al. 2008; Hovatta et al. 2005; Kumar and Chanana 2017; Haider et al. 2015; Hassan et al. 2013). There are only few emerging data in anxiety disorders, especially in generalized anxiety disorder (GAD) in humans. For example, Emhan et al. (2015) and Ercan et al. (2017) reported that patients with GAD demonstrate significantly higher total oxidant status and oxidative stress index than normal controls. Increased levels of lipid hydroperoxides $(\mathrm{LOOH})$ in GAD, indicating increased lipid peroxidation, were reported by Bulut et al. (2013). Moreover, Emhan et al. (2015) found that GAD is accompanied by lowered total antioxidant status, suggesting that oxidative stress may play a role in GAD. Other studies found lowered levels of specific antioxidants or antioxidant enzymes in GAD, including lowered free sulfhydryl groups and paraoxonase 1 (PON1), namely CMPAase activities (Bulut et al. 2013; Kaya et al. 2013). The results in social and simple phobias and panic disorder are more controversial (Atmaca et al. 2004; Hagan et al. 2015; Cengiz et al. 2015; Atasoy et al. 2015; Gul et al. 2013). Patients with anxiety disorders also show lowered levels of uric acid than controls (Black et al. 2018). Nevertheless, it remains unclear how specific aspects of the nitro-oxidative pathways ranging from antioxidant defenses to SOD activity, ROS production, lipid peroxidation, and the generation of aldehydes and oxidation protein products are differently altered in anxiety disorders or GAD.

There is a strong comorbidity between mood and anxiety disorders (Maes et al. 1994b; Merikangas et al. 2007) with the 12-month and lifetime prevalence of anxiety being as high as 57.5-59.2\% (Culpepper 2008; Fava et al. 2000). Among patients with major depression (MDD), prevalent anxiety disorders are social phobia (27.0\%), simple phobia (16.9\%), panic disorder (14.5\%) and GAD (10.6\%) (Fava et al. 2000). Interestingly, GAD is thought to belong to the mood disorders spectrum especially being related to MDD (Mennin et al. 2008). Among patients with bipolar disorder (BD), comorbid anxiety disorders may occur in up to $75 \%$ of individuals
(Hawke et al. 2013) with a high prevalence of GAD, social $(13.3 \%)$, and specific phobias $(10.8 \%)$ and panic disorder (16.8\%) (Hawke et al. 2013; Nabavi et al. 2015; Otto et al. 2004; Annigeri et al. 2011; Peng and Jiang 2015).

There is now abundant evidence that both MDD and BD are characterized by lowered lipid-associated antioxidant defenses which protect against damage to lipids, including attenuated activities of lecithin cholesterol acyltransferase (LCAT), glutathione peroxidase (GPx), and PON1 and lowered plasma concentrations of vitamin E, high-density lipoprotein (HDL)cholesterol, and coenzyme Q10 (Maes et al. 1994a, 1997, 1999a, 2000, 2009; Sobczak et al. 2004; Tsuboi et al. 2006; Bortolasci et al. 2014a; Nunes et al. 2015; Moreira et al. 2017; Liu et al. 2015). Secondly, these attenuated antioxidant defenses may contribute to increased generation of ROS and damage to lipids as measured with $\mathrm{LOOH}$ and oxidative indices of damage to lipid membranes (Peet et al. 1998; Maes et al. 1996, 1999a, 2011a, b; Moylan et al. 2014; Liu et al. 2015). Thirdly, findings in depression also show elevated production of inducible NO synthase (iNOS) and NO, which together with increased ROS may increase the potential to form peroxynitrite (Gałecki et al. 2012; Maes 2008; Maes et al. 2011b). Fourthly, different papers and meta-analyses report increased $\mathrm{MDA}$ or thiobarbituric acid reactive substances (TBARS) in MDD and BD (Bilici et al. 2001; Khanzode et al. 2003; Ozcan et al. 2004; Maes et al. 2011a; Liu et al. 2015; Mazereeuw et al. 2015; Andreazza et al. 2008; Brown et al. 2014).

Fifthly, patients with depression also show increased plasma levels of advanced oxidation protein products (AOPP), as observed in prenatal depression and depression due to chronic apical periodontitis (Gomes et al. 2017; Roomruangwong et al. 2017). A recent meta-analysis shows elevated levels of uric acid in patients with BD as compared with MDD patients and healthy controls (Bartoli et al. 2016). Uric acid is a major antioxidant in human blood, although increased levels may have pro-oxidant effects in the cell (Sautin and Johnson 2008). Nevertheless, there are no data whether the cooccurrence of mood and anxiety disorders is accompanied by more aberrations in nitro-oxidative pathways.

Thus, the aim of the present study was to examine levels of superoxide dismutase (SOD1), LOOH, catalase (CAT), NO metabolites (NOx), MDA, AOPP, PON1, HDL-cholesterol, reduced glutathione (GSH), and uric acid among individuals with GAD and to examine whether the comorbidity between GAD and mood disorders is characterized by incremental increases in nitro-oxidative stress. The a priori hypotheses were that GAD is accompanied by elevated oxidative and 
nitrosative stress (O\&NS) pathways and that the cooccurrence with mood disorders is associated with further increases in these pathways.

\section{Subjects and Methods}

\section{Participants}

In this cross-sectional study, we recruited 172 participants, 91 without and 81 with DSM-IV-TR anxiety disorders, namely generalized anxiety disorder (GAD), social phobia, simple phobia, and panic disorder. The study included 46 patients with GAD and 126 without GAD. All subjects were Brazilian, all ethnicities (self-declared), aged 20 to 63 years, and of both genders. They were outpatients admitted to the Psychiatry Department at the University Hospital of the State University of Londrina (UEL), Parana, Brazil, or healthy volunteers recruited by word of mouth from the same catchment area. We included individuals with any of these four anxiety disorders, MDD, BD, and tobacco use disorder (TUD). One hundred and five of the participants had co-occurring $\mathrm{BD}(n=68)$ or MDD $(n=37)$. The BD and MDD patients were all in (partial) remission and the index episode was not of (hypo)manic polarity. We excluded healthy controls and patients when they had other axis-1 DSM-IV-TR disorders, including autism, schizophrenia, schizo-affective disorder, substance abuse, and psycho-organic syndromes. We also excluded controls and patients with neuroinflammatory and neurodegenerative disorders (including multiple sclerosis, Alzheimer's disease, Parkinson's disease) and subjects with immune-inflammatory disorders, including psoriasis, rheumatoid arthritis, chronic obstructive pulmonary disease, cancer, chronic kidney disease, systemic lupus erythematosus, type 1 diabetes, hepatitis $\mathrm{B}$ and $\mathrm{C}$ virus, and HIV infection. Also, controls and patients treated with immunoregulatory drugs such as glucocorticoids, nonsteroidal antiinflammatory drugs, interferon, herbal, antioxidant, and omega-3 polyunsaturated fatty acid supplements were excluded. Pregnant women were not allowed to participate in this study. Some participants were treated with antidepressants $(n=44)$, lithium $(n=26)$, atypical antipsychotics $(n=32)$ or anticonvulsant mood stabilizers $(n=33)$. All participants gave written informed consent to take part in the current study, whose experimental procedures were previously approved by the Research Ethics Committee at UEL (protocol number: CAAE 34935814.2.0000.5231).

\section{Methods}

The clinical diagnoses of anxiety disorders, MDD, BD, and nicotine dependence or TUD were made by a research psychiatrist using the diagnostic criteria of the Diagnostic and Statistical Manual of Mental Disorders, 4th Edition, Text Revision (DSM-IV-TR) and a validated Portuguese version of the structured clinical interview for DSM-IV interview (SCID) axis I (Del-Ben et al. 2001; APA 2000). A structured interview comprised socio-demographic (marital status, selfdeclared ethnicity, years of education, employment status) and clinical (number of previous depressive, hypomanic, and manic episodes) data. The Hamilton Anxiety Rating Scale (HAMA) and the 17-item Hamilton Depression Rating Scale (HAMD) were employed to measure severity of anxiety and depression, respectively (Hamilton 1959, 1960). The Young Mania Rating Scale (YMRS) was used to measure severity of manic symptoms (Vilela et al. 2005). We used the Alcohol, Smoking, and Substance Involvement Screening Test (ASSIST) to assess misuse of alcohol and hypnotics (WHO Assist Working Group. 2002; Henrique et al. 2004). Body mass index (BMI) was computed according to weight (in $\mathrm{kg}$ ) divided by square of height (in $\mathrm{m}^{2}$ ).

\section{Assays}

Peripheral fasting $(12 \mathrm{~h})$ blood was sampled at 8 a.m. the same day as the diagnosis was made and clinical data were collected. We measured the activities of SOD, CAT, and PON1 and the concentrations of LOOH, NOx, MDA, uric acid, reduced glutathione (GSH), HDL-cholesterol, and AOPP. SOD1 activity in erythrocytes was determined using the pyrogallol method described by Marklund and Marklund (1974). This technique is based on the inhibition of pyrogallol self-oxidation by SOD in aqueous solution. The assay was conducted in a spectrophotometer Helios A, Thermo Spectronic (Waltham, MA, USA) at $420 \mathrm{~nm}$ and $37^{\circ} \mathrm{C}$. During $5 \mathrm{~min}$, variation in optical density (OD) was recorded every minute. The level of SOD that inhibited $50 \%$ of the pyrogallol oxidation was defined as one unit of enzymatic activity. The results were expressed U/mg of hemoglobin $(\mathrm{Hb})$. Measurement of CAT activity was estimated through the difference between the initial reading and the reading conducted $30 \mathrm{~s}$ after the addition of $200 \mathrm{mM} \mathrm{H}_{2} \mathrm{O}_{2} 30 \%$ at $240 \mathrm{~nm}$ in a microplate reader (model EnSpire, PerkinElmer, USA) with the temperature maintained at $25{ }^{\circ} \mathrm{C}$. CAT values are expressed as units per milligram of $\mathrm{Hb}$. $\mathrm{LOOH}$ are assayed by chemiluminescence (CL-LOOH) (Gonzalez et al. 1991; Panis et al. 2012). This method uses the compound tert-butyl hydroperoxide to start a lipid chain reaction that can be detected by photon emission during the formation of lipid hydroperoxides. Readings were performed in a Glomax luminometer (TD 20/20 Turner Designers, USA) over $1 \mathrm{~h}$ at one reading per second. Results are expressed as relative units of light. NOx levels were assessed indirectly by determining the plasma nitrite concentration using an 
adaptation of the technique described by NavarroGonzalvez et al. (1998). This method is based on the reduction of the nitrate present in the sample to nitrite by oxidation-reduction reactions mediated by the system cadmium-copper reagent. Thereafter, Griess reagent was added to induce diazotization, forming a colored complex and subsequent detection at $540 \mathrm{~nm}$. The quantification of NOx was made in a microplate reader Asys Expert Plus, Biochrom (Holliston, MA, USA). NOx concentrations were expressed in molars. MDA levels were measured through complexation with two molecules of thiobarbituric acid (TBA) using MDA estimation through highperformance liquid chromatography (HPLC Alliance e2695, Waters', Barueri, SP, Brasil) (Bastos et al. 2012). Experimental conditions included the use of a column Eclipse XDB-C18 (Agilent, USA), mobile phase consisting of $65 \%$ phosphate buffer $(50 \mathrm{nM} \mathrm{pH} \mathrm{7.0)}$ and $35 \%$ HPLC grade methanol, flow rate of $1.0 \mathrm{~mL} / \mathrm{min}$, temperature of $30{ }^{\circ} \mathrm{C}$, and wavelength of $532 \mathrm{~nm}$. MDA concentration in the samples was quantified based on a calibration curve and is expressed in millimoles of MDA per milligram of proteins. HDL cholesterol was measured by enzymatic colorimetric method in an automated clinical chemistry system (Dimension RXL, Siemens, USA). GSH was measured with a kinetic/colorimetric method using hemolysate (diluted $1 / 40$ ) as the sample following the technique described by Tietze (1969) and Anderson (1985). Uric acid was measured by an U.V. enzymatic method (direct equilibrium uricase method) in an automated clinical chemistry system (Dimension RXL, Siemens, USA). PON1 status (i.e., PON1 total activity and PON1 Q192R polymorphism) was measured using three kinetic assays (Richter et al. 2009) conducted in a microplate reader (EnSpire, PerkinElmer, USA). To stratify individuals in the functional genotypes for the PON1 Q192R polymorphism (QQ, QR, and RR), the substrates used were phenyl acetate (PA, Sigma, USA) under high salt condition and 4-(chloromethyl)phenyl acetate (CMPA, Sigma, USA), which is an alternative to the use of the toxic paraoxon. PON1 total activity was determined by the rate of hydrolysis of phenyl acetate under low salt condition at $270 \mathrm{~nm}$ and $25^{\circ} \mathrm{C}$. The activity was expressed in units per milliliter based on the phenyl acetate molar extinction coefficient of $1.31 \mathrm{mmol} / \mathrm{L} / \mathrm{cm}$. In the present study, we adjusted PON1 activity values for the genotypes and used the residualized values in subsequent analyses. AOPP was quantified using the method described by Hanasand et al. (2012) in a microplate reader, PerkinElmer, model EnSpire (Waltham, MA, USA) at a wavelength of $340 \mathrm{~nm}$. AOPP concentration was expressed in molars of equivalent chloramine $\mathrm{T}$. All interassay $\mathrm{CV}$ values for all assays were $<7 \%$.

Figure 1 shows the paths from superoxide formation to lipid peroxidation and aldehyde and AOPP formation. In order to examine these pathways and the antioxidant defenses (CAT, GSH, PON1, HDL-cholesterol), we computed composite scores reflecting different parts of the pathways.

\section{Use of $z$ Unit-Weighted Composite Scores}

Using the separate O\&NS biomarkers, one may estimate the separate activities of antioxidant enzymes (SOD1, catalase, PON1) and products of lipid peroxidation (LOOH), aldehyde production (MDA), and protein oxidation (AOPP). Nevertheless, these values do not allow to examine the balance between pro-oxidant and antioxidant profiles as well as the pathways from ROS production to nitro-oxidative damage. In order to estimate pro-oxidative/antioxidant balances and the activity of nitro-oxidative pathways, we have computed $z$ unit-weighted composite scores. The advantage of using composite scores was explained previously using cytokine and nitro-oxidative data (Maes et al. 1998, 1999b; Kubera et al. 2001; Sowa-Kućma et al. 2017, 2018; Guimarães et al. 2017; Moraes et al. 2018). Recently, we have summarized the rationale to compute $z$ unit-weighted composite scores (Maes and Carvalho 2018). For example, to estimate the combined protective effects of PON1 and HDL-cholesterol (see the "Introduction" and "Discussion" sections), we have computed a composite score as $z$ value of PON1 $(z \mathrm{PON} 1)+z$ HDLcholesterol. Since both data are expressed in different units, it is not possible to use a simple sum of both factors. Both variables however become comparable after standardization for example using a $z$ transformation, which is the actual value of the measurement in relation to the standard deviation of the sample. Another advantage is that the computed $z$ unitweighted composite score indicates the location of a patient (or a group of patients) in the $z(z \mathrm{PON} 1+z$ HDL-cholesterol) data distribution with mean $=0$ and $\mathrm{SD}=1$. In the present study, we computed the following $z$ composite scores:

a) $z \mathrm{SOD} 1+\mathrm{LOOH}$ computed as $z$ transformation of SOD values $(z \mathrm{SOD} 1)+z \mathrm{LOOH}$. SOD is an antioxidant enzyme which partitions superoxide radicals into oxygen and hydrogen peroxides (Fukai and Ushio-Fukai 2011; McCord and Edeas 2005; Hayyan et al. 2016). Importantly, SOD1 mRNA is constitutively expressed and is additionally regulated by (patho)physiological factors (Zelko et al. 2002; Miao and St Clair 2009). SOD1 expression is stimulated by hydrogen peroxide, nitric oxide, arachidonic acid, and $\mathrm{T}$ cell-mediated mechanisms (Zelko et al. 2002; Harris 1992; Terrazzano et al. 2014). Moreover, the SOD1 promotor has a nuclear factor (NF)-KB site which is responsive to the PI3K/Akt pathway (Rojo et al. 2004). Thus, while SOD1 functions as an antioxidant mediating superoxide $\left(\mathrm{O}_{2}{ }^{\bullet-}\right)$ dismutation it is a major source of (the less reactive) hydrogen peroxides, especially in the presence of nitro-oxidative stress and 


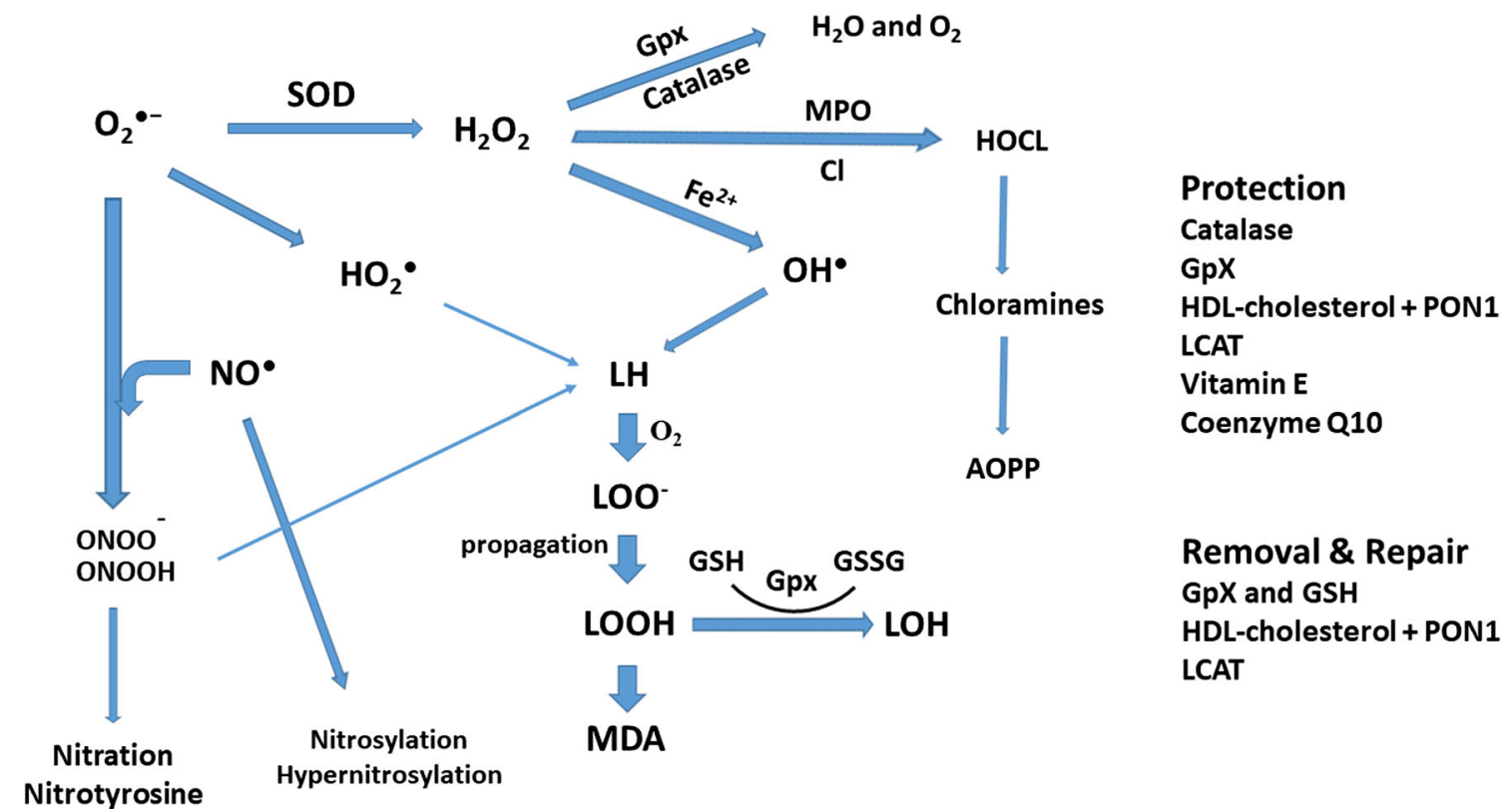

Fig. 1 Increased superoxide $\left(\mathrm{O}_{2}{ }^{\bullet-}\right)$ is frequently associated with activated superoxide dismutase (SOD) activity. SOD catalyzes $\mathrm{O}_{2}{ }^{\bullet-}$ into peroxides $\left(\mathrm{H}_{2} \mathrm{O}_{2}\right)$. Catalase and also glutathione peroxidase $(\mathrm{Gpx})$ activate the decomposition of $\mathrm{H}_{2} \mathrm{O}_{2}$ into water and oxygen. In the presence of $\mathrm{Fe}^{2+}$ (the Fenton reaction), highly reactive hydroxyl radicals $\left(\mathrm{OH}^{\bullet}\right)$ are formed which coupled with peroxynitrite $\left(\mathrm{ONOO}^{-}\right)$and perhydroxyl radicals $\left(\mathrm{HO}_{2}{ }^{\bullet}\right)$ damage lipid membranes, thereby generating fatty acid radicals which react with oxygen to form lipid peroxy $\left(\mathrm{LOO}^{-}\right)$radicals. The latter in turn react with other lipids thereby generating lipid hydroperoxides ( $\mathrm{LOOH})$. This further damages lipid membranes, and consequently, aldehydes are formed including malondialdehyde (MDA). Increased myeloperoxidase (MPO) activity may generate the very reactive

immune activation. Depending on the activity of catalase and GPx and $\mathrm{Fe}^{2+}$ levels (see Fig. 1), this may contribute to elevated production of hydroxyl $\left(\mathrm{OH}^{\bullet}\right)$ radicals (Girotti 1998). Hydrogen peroxides and hydroxyl radicals induce the formation of $\mathrm{LOOH}$, which is mainly derived from cholesterol and unsaturated phospholipids (Girotti 1998). Therefore, the sum $z \mathrm{LOOH}+z$ SOD reflects ROS (e.g., hydrogen peroxide + hydroxyl radical production) driving lipid peroxidation.

b) $z \mathrm{SOD}+\mathrm{LOOH}+\mathrm{NOx}$ computed as $z \mathrm{SOD}+z \mathrm{LOOH}+$ $z N O x$. This $z$-based composite score reflects peroxide, peroxyl, and hydroxyl production coupled with the production of NO, which together with superoxide increases the potential to form peroxynitrite (Girotti 1998; Pacher et al. 2007). Therefore, this score reflects ROS + RNS production or nitro-oxidative stress leading to lipid (and protein) oxidation.

c) $z(z \mathrm{SOD}+z \mathrm{LOOH}+z \mathrm{NOx})+z \mathrm{MDA}$ computed as $z(z \mathrm{SOD}+z \mathrm{LOOH}+z \mathrm{NOx})+z \mathrm{MDA} . \mathrm{MDA}$ is the end product of lipid peroxidation. Therefore, this score reflects the path from ROS/RNS (nitro-oxidative stress) to lipid peroxidation and ultimately aldehyde production (Maes et al. 2011a). hypochlorous acid ( $\mathrm{HOCl}$ ), which may lead to damage to proteins including the generation of advanced oxidation protein products (AOPPs). Increased nitric oxide production (NO) coupled with increased $\mathrm{O}_{2}{ }^{\bullet-}$ generates peroxynitrite $\left(\mathrm{ONOO}^{-}\right)$which leads to lipid peroxidation. Moreover, increased NO and peroxynitrite production may damage proteins through formation of nitrotyrosine (through nitration) and $\mathrm{NO}$ adducts (through nitrosylation), respectively (Roomruangwong et al. 2018; Morris et al. 2017). Antioxidant defenses protect against lipid peroxidation and may repair and remove lesions, including glutathione peroxidase (Gpx), catalase, L-lecithin/cholesterol acyltransferase (LCAT), paraoxonase 1 (PON1), high-density-lipoprotein (HDL) cholesterol, vitamin E, and coenzyme Q10

d) $z(z \mathrm{SOD}+\mathrm{LOOH}+\mathrm{NOx})+z \mathrm{AOPP}$ computed as $z(z \mathrm{LOOH}+z \mathrm{SOD}+z \mathrm{NOx})+z \mathrm{AOPP}$. This $z$ unitweighted composite score reflects the path from increased ROS/RNS production leading to protein oxidation (AOPP) via increased ROS and peroxynitrite production coupled with increased myeloperoxidase (MPO) activity and hypochlorous acid production (Witko-Sarsat et al. 1996).

e) $z(z \mathrm{SOD}+z \mathrm{LOOH}+z \mathrm{NOx})+z(\mathrm{MDA}+\mathrm{AOPP})$ computed as $z(z \mathrm{LOOH}+z \mathrm{SOD}+z \mathrm{NOx})+z(\mathrm{MDA}+z \mathrm{AOPP})$. This is an integrate index of nitro-oxidative stress leading to lipid peroxidation with aldehyde formation and protein oxidation.

f) $z \mathrm{CAT}+\mathrm{GSH}$ computed as $z \mathrm{CAT}+z \mathrm{GSH}$. This $z$ unitweighted composite score reflects part of the antioxidant defenses against lipid peroxidation. Catalase and GPx catalyze the decomposition of peroxides into oxygen and water, while GPx (and GSH, which maintains GPx levels) degrades $\mathrm{LOOH}$ into the harmless $\mathrm{LOH}$.

g) $z \mathrm{HDL}+\mathrm{PON} 1$ computed as $z \mathrm{HDL}$-cholesterol $+z \mathrm{PON} 1$. This score reflects lipid-associated antioxidant defenses through HDL-cholesterol and PON1 activity which protects against lipid peroxidation and may remove lipid peroxides and aldehydes from the circulation. 
h) $z$ sum5OX $-z$ sum4ANTIOX computed as $z(z \mathrm{SOD}+$ $z \mathrm{LOOH}+z \mathrm{NOx}+z \mathrm{MDA}+z \mathrm{AOPP})-z(z \mathrm{HDL}-$ choles terol $+z \mathrm{PON} 1+z \mathrm{GSH}+z \mathrm{CAT})$. This composite score reflects the balance between overall nitro-oxidative stress and antioxidant defenses.

i) $\quad z$ Uric acid was introduced in the analysis as a separate variable because uric acid may act as an antioxidant and pro-oxidant.

\section{Statistical Analyses}

We used analyses of variance (ANOVAs) to compute differences in scale variables between diagnostic groups and analyses of contingency tables ( $\chi^{2}$ tests) to assess differences in nominal variables between diagnostic groups. Results of multiple comparisons were p-corrected for false discovery rate according to Benjamini and Hochberg (1995). We employed binary logistic regression analyses to assess the most significant predictors of diagnosis, e.g., GAD as dependent variable and no GAD as reference group. Odds ratios and $95 \%$ confidence intervals are computed and Nagelkerke values are employed as effect size estimates. We used multivariate GLM analysis with the nitro-oxidative stress biomarkers as dependent variables and diagnosis as primary explanatory variable, while adjusting the data for sex, age, BMI, education, and TUD. Consequently, we used tests for between-subject effects to assess the effects of explanatory variables on the separate O\&NS biomarkers. We computed model-derived estimated marginal means to assess differences among diagnostic categories. In order to analyze the comorbidity between mood and GAD (or anxiety disorders), we use multivariate GLM analyses to examine differences in the biomarkers among the study groups with or without GAD (or anxiety disorders) yielding six study groups, namely (a) controls, (b) $\mathrm{GAD}$, (c) BD, (d) $\mathrm{BD}+\mathrm{GAD}$, (e) $\mathrm{MDD}$, and (f) MDD + GAD. IBM SPSS Windows version 22, Statistica 8, and Stata were used to analyze all data. Statistical significance was set at 0.05 , two-tailed.

\section{Results}

\section{Descriptive Statistics}

Table 1 shows the demographic and clinical data in participants with and without GAD. After p-correction for false discovery rate, we found higher HAM-D and HAM-A scores in GAD patients as compared with those without GAD, while there were no differences in the YMRS score. There was a significant association between GAD and simple and social phobias and mood disorders (either BD or MDD), but not between GAD and panic disorder or TUD. There were no significant differences in age, sex, education, BMI, and employment and marital status, and number of depressive and (hypo)manic episodes between both groups. Table 1 shows also the raw data for the 10 biomarker measurements and the results of univariate ANOVAs. We want to stress that these raw data are not interpretable because the results were not adjusted for age, sex, BMI, TUD, and the presence of mood disorders. Below we will present the adjusted data. Figure 2 shows the $z$-transformed values of these 10 O\&NS biomarkers (unadjusted data) in participants with and without GAD.

The intercorrelation matrix among the 10 O\&NS biomarkers showed that there were significant and positive correlations (without p-correction) between CAT and GSH ( $r=$ $0.385, p<0.001, n=143)$, SOD1 and MDA $(r=0.331$, $p<0.001, n=146)$, LOOH and AOPP $(r=0.253, p<0.001$, $n=149)$, SOD1 and GSH $(r=0.277, p=0.001, n=143)$, uric acid and AOPP $(r=0.478, p<0.001, n=147)$, and PON1 and HDL-cholesterol $(r=0.296, p<0.001, n=149)$. There were significantly inverse correlations between LOOH and PON1 $(r=-0.206, p=0.012, n=149)$ and uric acid and HDLcholesterol $(r=-0.321, p<0.001, n=0.152)$. There were also significant and negative correlations between $z \mathrm{HDL}+$ PON1 and $z \mathrm{SOD}+\mathrm{LOOH}(r=-0.195, p=0.018, n=145)$, $z \mathrm{SOD}+\mathrm{LOOH}+\mathrm{NOx}(r=-0.229, p=0.007, n=137)$, $z(z \mathrm{SOD}+z \mathrm{LOOH}+z \mathrm{NOx})+z \mathrm{MDA}(r=-0.247, p=0.004$, $n=136), z(z \mathrm{SOD}+z \mathrm{LOOH}+z \mathrm{NOx})+z \mathrm{AOPP}(r=-0.345$, $p<0.001, n=137)$, AOPP $(r=-0.293, p<0.001, n=149)$ and $z(z \mathrm{SOD}+z \mathrm{LOOH}+z \mathrm{NOx})+z(\mathrm{MDA}+\mathrm{AOPP})(r=-$ $0.356, p<0.001, n=136$ ).

\section{Differences in O\&NS Biomarkers Among Patients with and without GAD}

Table 2 shows the outcome of 3 multivariate GLM analyses with the 10 O\&NS biomarkers (listed in Table 1) as dependent variables and GAD as primary explanatory variable, while adjusting for age, sex, BMI, mood disorder diagnosis (controls versus MDD versus BD), TUD, and education. Regression no. 1 shows that GAD had a significant effect on the 10 O\&NS biomarkers, independently from the effects of diagnoses (controls versus MDD versus BD), TUD, BMI, and sex. There was also a significant effect of GAD $\times$ TUD interaction (for the effects of the extraneous/confounder variables: see below). Tests for between-subject effects showed significant effects of GAD on SOD1, LOOH, NOx, PON1, HDL-cholesterol, and uric acid. Table 3 shows the model-generated estimated marginal mean values of the six significant O\&ND biomarkers in both groups. SOD1, LOOH, NOx, and uric acid were significantly higher in GAD patients than in those without, while PON1 and HDL-cholesterol were significantly lower in GAD. The same table also shows the interaction GAD $\times$ TUD with significantly higher NOx, MDA, and uric acid levels in GAD subjects without TUD, but not in non smokers. 
Table 1 Socio-demographic, clinical, and biomarker data in participants with and without generalized anxiety disorders (GAD)

\begin{tabular}{|c|c|c|c|c|c|}
\hline Variables & No $\operatorname{GAD}(n=126)$ & $\operatorname{GAD}(n=46)$ & $F$ & $\mathrm{df}$ & $p^{\mathrm{b}}$ \\
\hline Age (years) & $43.0(11.4)$ & $42.3(10.7)$ & 0.12 & $1 / 170$ & 0.728 \\
\hline $\operatorname{Sex}(\mathrm{F} / \mathrm{M})$ & $94 / 32$ & $35 / 11$ & 0.04 & 1 & 0.842 \\
\hline Education (years) & $11.5(5.5)$ & $10.3(4.2)$ & 1.66 & $1 / 169$ & 0.199 \\
\hline Body mass index $\left(\mathrm{kg} / \mathrm{m}^{2}\right)$ & $26.5(5.0)$ & $26.4(4.2)$ & 0.01 & $1 / 163$ & 0.919 \\
\hline Employment status (no/yes) & $51 / 74$ & $22 / 24$ & 0.68 & 1 & 0.410 \\
\hline Single/married/separated + widowed & $32 / 70 / 24$ & $6 / 27 / 13$ & 3.72 & 2 & 0.156 \\
\hline HAM-D & $6.1(6.0)$ & $10.2(7.2)$ & 14.08 & $1 / 170$ & $<0.001(0.005)$ \\
\hline YMRS & $1.4(2.6)$ & $1.6(2.3)$ & 1.35 & $1 / 170$ & 0.643 \\
\hline HAMA & $10.2(8.6)$ & $17.1(12.0)$ & 16.0 & $1 / 159$ & $<0.001(0.005)$ \\
\hline Number depressive episodes & $2.9(4.3)$ & $4.2(4.8)$ & 2.43 & $1 / 161$ & 0.121 \\
\hline Number manic episodes & $2.2(4.8)$ & $3.9(6.4)$ & 3.33 & $1 / 170$ & 0.070 \\
\hline Social phobia (no/yes) & $122 / 4$ & $36 / 10$ & 15.53 & 1 & $<0.001(0.005)$ \\
\hline Simple phobias (no/yes) & $108 / 18$ & $25 / 21$ & 18.91 & 1 & $<0.001(0.005)$ \\
\hline Panic disorder (no/yes) & $107 / 19$ & $38 / 8$ & 0.14 & 1 & 0.712 \\
\hline No mood disorders/BD/MDD & $59 / 44 / 23$ & $8 / 24 / 14$ & 12.36 & 2 & $0.002(0.008)$ \\
\hline Tobacco use disorder (no/yes) & $57 / 69$ & $20 / 26$ & 0.04 & 1 & 0.837 \\
\hline Antidepressants (no/yes) & $87 / 31$ & $27 / 17$ & 2.35 & 1 & 0.125 \\
\hline Antipsychotics (no/yes) & $98 / 20$ & $32 / 12$ & 2.16 & 1 & 0.142 \\
\hline Lithium (no/yes) & $101 / 16$ & $34 / 10$ & 1.94 & 1 & 0.164 \\
\hline Mood stabilizers (no/yes) & $94 / 23$ & $34 / 10$ & 0.19 & 1 & 0.667 \\
\hline SOD1 (U/mg Hb) & $92.8(38.0)$ & $112.5(44.0)$ & 7.11 & $1 / 145$ & 0.009 \\
\hline $\mathrm{LOOH}\left(\mathrm{RLU} \times 10^{6}\right)^{\mathrm{a}}$ & $1504(1115)$ & 1808 (1039) & 2.33 & $1 / 147$ & 0.129 \\
\hline CAT (U/mg Hb) & $59.4(14.9)$ & $63.1(13.2)$ & 1.91 & $1 / 144$ & 0.169 \\
\hline $\mathrm{GSH}(\mathrm{mM} / \mathrm{gHb})$ & $5.64(1.03)$ & $5.77(1.18)$ & 0.40 & $1 / 141$ & 0.530 \\
\hline Uric acid $(\mathrm{mg} / \mathrm{dL})^{\mathrm{a}}$ & $4.54(1.44)$ & $4.93(1.36)$ & 2.25 & $1 / 151$ & 0.136 \\
\hline MDA (mmol/mg protein) ${ }^{\mathrm{a}}$ & $63.5(21.6)$ & $67.8(22.0)$ & 1.20 & $1 / 147$ & 0.275 \\
\hline $\mathrm{AOPP}(\mu \mathrm{M})$ & $77.8(42.5)$ & $89.3(47.3)$ & 1.80 & $1 / 148$ & 0.182 \\
\hline $\operatorname{NOx}(\mu \mathrm{M})^{\mathrm{a}}$ & $6.2(2.7)$ & $7.7(4.8)$ & 6.19 & $1 / 148$ & 0.014 \\
\hline PON1 (U/L) & $213.3(55.4)$ & $183.8(53.7)$ & 8.76 & $1 / 148$ & 0.004 \\
\hline HDL (mg/dL) & $49.8(16.5)$ & $44.6(10.6)$ & 3.60 & $1 / 157$ & 0.060 \\
\hline
\end{tabular}

All results are shown as mean $( \pm \mathrm{SD}) . F$ : results of analyses of variance; $\chi^{2}$ : results of analyses of contingency tables

$B D$ bipolar disorders, $M D D$ major depression, $S O D$ superoxide dismutase, $L O O H$ lipid hydroperoxides, CAT catalase, GSH glutathione, $M D A$ malondialdehyde, $A O P P$ advanced oxidation protein products, $N O x$ nitric oxide metabolites, $P O N 1$ paraoxonase $1, H D L$ high-density lipoprotein cholesterol

${ }^{\mathrm{a}}$ These data are processed in Ln transformation

${ }^{\mathrm{b}} p$ values between brackets: $p$ values after $\mathrm{p}$-correction for false discovery rate

We have examined whether the effects of GAD were still present after considering the effects of severity of anxiety and severity of mood disorders by entering HAM-A and HAM-D and YMRS, respectively. Multivariate GLM analysis no. 2 shows that HAM-A has a significant effect on the biomarkers and that the effects of GAD and GAD $\times$ TUD remained significant. Tests for between-subject effects show that HAM-A score is positively associated with $\mathrm{LOOH}(F=8.48, \mathrm{df}=1$ / 106, $p=0.004$; partial eta squared $=0.074)$ and AOPP $(F=$ $7.40, \mathrm{df}=1 / 106, p=0.008$; partial eta squared $=0.065$ ). Multivariate GLM analysis no. 3 shows that HAM-D, but not YMRS, has a significant effect on the 10 biomarkers, while the effects of GAD and GAD $\times$ TUD remained significant. Tests for between-subject effects show that the HAM-D score is positively associated with $\mathrm{LOOH}(F=5.38, \mathrm{df}=1 /$ $114, p=0.022$; partial eta squared $=0.045)$ and $\operatorname{AOPP}(F=$ $20.10, \mathrm{df}=1 / 114, p<0.001$; partial eta squared $=0.150$ ).

We also performed similar multivariate GLM analyses with the presence of other anxiety disorders (social phobia, simple phobia, or panic disorder) $(F=1.50, \mathrm{df}=10 / 108, p=0.148)$ and all anxiety disorders combined (GAD, social phobia, simple phobia, or panic disorder $)(F=1.91, \mathrm{df}=10 / 107, p=$ 
Fig. 2 Measurements (in $z-$ transformations) of 10 nitrooxidative stress biomarkers in participants with (1) and without (0) generalized anxiety disorder. SOD superoxide dismutase, CAT catalase, LOOH lipid hydroperoxides, NOx nitric oxide metabolites, MDA malondialdehyde, AOPP advanced oxidation protein products, GSH reduced glutathione, UA uric acid, HDL high-density lipoprotein cholesterol, PON1 paraoxonase 1

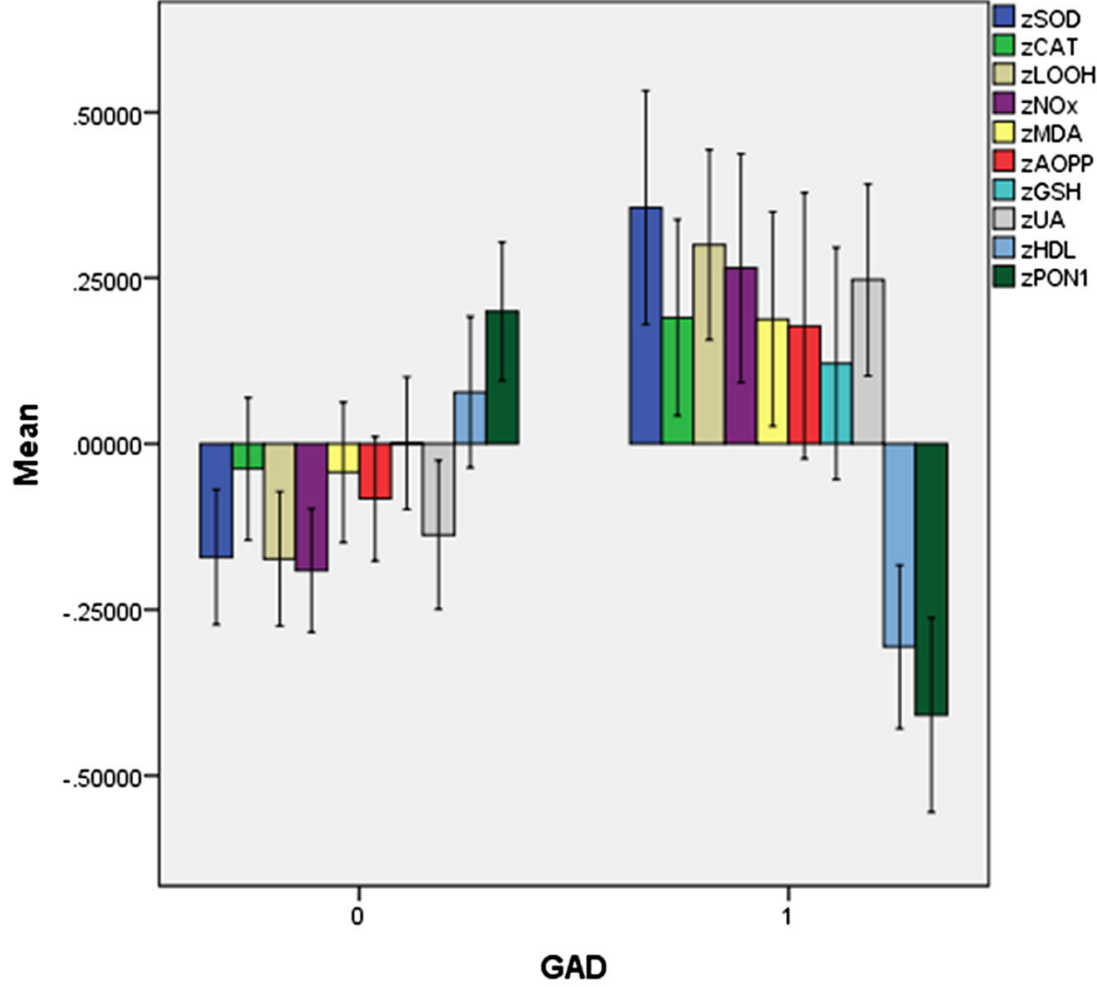

Error bars: +/- $1 \mathrm{SE}$
0.051 ) as explanatory variables (and using the same independent variables as shown in Table 2) but could not find significant effects on the 10 biomarkers. This indicates that GAD, but not the other anxiety disorders, has a significant impact on the O\&NS biomarkers.

\section{Differences in Composite Scores Among Patients with and without GAD}

Table 4, regression no. 2, shows the results of a multivariate GLM analysis with the nine composite scores as dependent variables and anxiety disorders as primary explanatory variables, while adjusting for sex, age, education, TUD, BMI, and diagnosis (controls versus MDD versus BD). There was a significant effect of GAD (regression no. 1) on the composite scores. Table 5 shows the modelgenerated estimated marginal mean values in both subjects with and without GAD. zSOD + LOOH, zSOD + $\mathrm{LOOH}+$ $\mathrm{NOx}, z(z \mathrm{SOD}+z \mathrm{LOOH}+z \mathrm{NOx})+z \mathrm{MDA}, z(z \mathrm{SOD}+$ $z \mathrm{LOOH}+z \mathrm{NOx})+z \mathrm{AOPP}, z(z \mathrm{SOD}+z \mathrm{LOOH}+z \mathrm{NOx})+$ $z(\mathrm{MDA}+\mathrm{AOPP})$, and $z$ sum5OX $-z$ sum4ANTIOX were significantly higher and $z \mathrm{HDL}+\mathrm{PON} 1$ significantly lower in participants with GAD than in those without GAD. Figure 3 shows the different composite scores in subjects with GAD versus those without GAD.
We have also adjusted the differences between GAD and non-GAD subjects for effects of severity of illness. Multivariate analysis no. 2 shows that HAM-A has no significant effect on the composite scores, while the effects of GAD and GAD $\times$ TUD remained significant. Multivariate analysis no. 3 shows that HAM-D, but not YMRS, has a significant effect on the composite scores, while the effects of GAD and GAD $\times$ TUD remain significant. There were significant effects of the HAM-D on $z(z \mathrm{SOD}+z \mathrm{LOOH}+z \mathrm{NOx})+z \mathrm{AOPP}$ $(F=13.17, \mathrm{df}=1 / 114, p=0.001$, partial eta squared $=0.104)$ and $z(z \mathrm{SOD}+z \mathrm{LOOH}+z \mathrm{NOx})+z(\mathrm{MDA}+\mathrm{AOPP})(F=5.07$, $\mathrm{df}=1 / 114, p=0.025$, partial eta squared $=0.043)$. We also performed a multivariate GLM analyses with the presence of any other anxiety disorder (social phobia, simple phobia or panic disorder) as explanatory variable but could not find a significant effect on the composite scores $(F=2.05, \mathrm{df}=7$ / $111, p=0.054)$.

\section{Interaction Patterns Between Mood and Anxiety Disorders}

In order to examine the co-occurrence between mood and GAD, we used multivariate GLM analyses to examine the effects of diagnosis on the biomarkers, namely six study samples divided into controls, GAD, BD, BD + GAD, 
Table 2 Results of multivariate general linear model (GLM) analysis with nine oxidative and nitrosative stress biomarkers as dependent variables and diagnoses as explanatory variables, while controlling for age, sex, body mass index (BMI), and tobacco use disorder (TUD)

\begin{tabular}{|c|c|c|c|c|c|c|}
\hline Type test & Dependent variables & Explanatory variables & $F$ & df & $P$ & Partial eta squared \\
\hline Multivariate $\neq 1$ & All 10 O\&NS variables & $\begin{array}{l}\text { GAD } \\
\text { GAD } \times \text { TUD } \\
\text { HC/BD/MDD } \\
\text { TUD } \\
\text { Sex } \\
\text { BMI } \\
\text { Education }\end{array}$ & $\begin{array}{l}4.25 \\
2.42 \\
1.64 \\
2.48 \\
6.23 \\
3.95 \\
2.33\end{array}$ & $\begin{array}{l}10 / 107 \\
10 / 107 \\
20 / 216 \\
10 / 107 \\
10 / 107 \\
10 / 107 \\
10 / 107\end{array}$ & $\begin{array}{l}<0.001 \\
0.012 \\
0.045 \\
0.010 \\
<0.001 \\
<0.001 \\
0.016\end{array}$ & $\begin{array}{l}0.284 \\
0.184 \\
0.132 \\
0.188 \\
0.368 \\
0.270 \\
0.179\end{array}$ \\
\hline Between-subject effects & $\begin{array}{l}\text { SOD1 } \\
\text { LOOH } \\
\text { NOx } \\
\text { PON1 } \\
\text { HDL } \\
\text { Uric acid }\end{array}$ & $\begin{array}{l}\text { GAD } \\
\text { GAD } \\
\text { GAD } \\
\text { GAD } \\
\text { GAD } \\
\text { GAD }\end{array}$ & $\begin{array}{l}4.93 \\
4.55 \\
9.65 \\
7.07 \\
4.81 \\
11.05\end{array}$ & $\begin{array}{l}1 / 116 \\
1 / 116 \\
1 / 116 \\
1 / 116 \\
1 / 116 \\
1 / 116\end{array}$ & $\begin{array}{l}0.028 \\
0.035 \\
0.002 \\
0.009 \\
0.030 \\
0.001\end{array}$ & $\begin{array}{l}0.041 \\
0.038 \\
0.077 \\
0.057 \\
0.040 \\
0.087\end{array}$ \\
\hline Between-subject effects & $\begin{array}{l}\text { NOx } \\
\text { MDA } \\
\text { Uric acid }\end{array}$ & $\begin{array}{l}\text { GAD } \times \text { TUD } \\
\text { GAD } \times \text { TUD } \\
\text { GAD } \times \text { TUD }\end{array}$ & $\begin{array}{l}8.90 \\
4.92 \\
4.23\end{array}$ & $\begin{array}{l}1 / 116 \\
1 / 116 \\
1 / 116\end{array}$ & $\begin{array}{l}0.003 \\
0.030 \\
0.042\end{array}$ & $\begin{array}{l}0.071 \\
0.039 \\
0.035\end{array}$ \\
\hline Between-subject effects & SOD1 & $\mathrm{HC} / \mathrm{BD} / \mathrm{MDD}$ & 4.08 & $1 / 116$ & 0.019 & 0.066 \\
\hline Between-subject effects & $\begin{array}{l}\text { SOD1 } \\
\text { LOOH } \\
\text { PON1 } \\
\text { HDL }\end{array}$ & $\begin{array}{l}\text { TUD } \\
\text { TUD } \\
\text { TUD } \\
\text { TUD }\end{array}$ & $\begin{array}{l}5.81 \\
7.58 \\
5.46 \\
5.10\end{array}$ & $\begin{array}{l}1 / 116 \\
1 / 116 \\
1 / 116 \\
1 / 116\end{array}$ & $\begin{array}{l}0.017 \\
0.007 \\
0.021 \\
0.026\end{array}$ & $\begin{array}{l}0.048 \\
0.061 \\
0.045 \\
0.042\end{array}$ \\
\hline Between-subject effects & $\begin{array}{l}\text { CAT } \\
\text { LOOH } \\
\text { AOPP } \\
\text { HDL } \\
\text { Uric acid }\end{array}$ & $\begin{array}{l}\text { Sex } \\
\text { Sex } \\
\text { Sex } \\
\text { Sex } \\
\text { Sex }\end{array}$ & $\begin{array}{l}5.25 \\
6.69 \\
24.25 \\
6.66 \\
36.35\end{array}$ & $\begin{array}{l}1 / 116 \\
1 / 116 \\
1 / 116 \\
1 / 116 \\
1 / 116\end{array}$ & $\begin{array}{l}0.024 \\
0.011 \\
<0.001 \\
0.011 \\
<0.001\end{array}$ & $\begin{array}{l}0.043 \\
0.054 \\
0.173 \\
0.054 \\
0.239\end{array}$ \\
\hline Between-subject effects & $\begin{array}{l}\text { AOPP } \\
\text { HDL } \\
\text { Uric acid }\end{array}$ & $\begin{array}{l}\text { BMI } \\
\text { BMI } \\
\text { BMI }\end{array}$ & $\begin{array}{l}4.11 \\
17.28 \\
17.39\end{array}$ & $\begin{array}{l}1 / 116 \\
1 / 116 \\
1 / 116\end{array}$ & $\begin{array}{l}0.045 \\
<0.001 \\
<0.001\end{array}$ & $\begin{array}{l}0.034 \\
0.130 \\
0.130\end{array}$ \\
\hline Between-subject effects & $\begin{array}{l}\text { SOD1 } \\
\text { CAT } \\
\text { MDA }\end{array}$ & $\begin{array}{l}\text { Education } \\
\text { Education } \\
\text { Education }\end{array}$ & $\begin{array}{l}8.82 \\
6.04 \\
4.76\end{array}$ & $\begin{array}{l}1 / 116 \\
1 / 116 \\
1 / 116\end{array}$ & $\begin{array}{l}0.004 \\
0.015 \\
0.031\end{array}$ & $\begin{array}{l}0.071 \\
0.050 \\
0.039\end{array}$ \\
\hline Multivariate $\neq 2$ & All 10 O\&NS variables & $\begin{array}{l}\text { GAD } \\
\text { GAD } \times \text { TUD } \\
\text { HAM-A }\end{array}$ & $\begin{array}{l}3.57 \\
2.65 \\
1.98\end{array}$ & $\begin{array}{l}10 / 97 \\
10 / 97 \\
10 / 97\end{array}$ & $\begin{array}{l}<0.001 \\
0.007 \\
0.043\end{array}$ & $\begin{array}{l}0.269 \\
0.215 \\
0.170\end{array}$ \\
\hline Multivariate $\neq 3$ & All 10 O\&NS variables & $\begin{array}{l}\text { GAD } \\
\text { GAD } \times \text { TUD } \\
\text { HAM-D } \\
\text { YMRS }\end{array}$ & $\begin{array}{l}4.10 \\
2.35 \\
2.75 \\
1.42\end{array}$ & $\begin{array}{l}10 / 105 \\
10 / 105 \\
10 / 105 \\
10 / 105\end{array}$ & $\begin{array}{l}<0.001 \\
0.015 \\
0.005 \\
0.181\end{array}$ & $\begin{array}{l}0.281 \\
0.183 \\
0.208 \\
0.119\end{array}$ \\
\hline
\end{tabular}

$G A D$ generalized anxiety disorder, $H C / B D / M D D$ healthy controls/bipolar disorder/major depression, HAM-A Hamilton Anxiety Rating Scale score, HAM-D Hamilton Depression Rating Scale score, YMRS Young Mania Rating Scale, SOD superoxide dismutase, CAT catalase, $L O O H$ lipid hydroperoxides, $N O x$ nitric oxide metabolites, $M D A$ malondialdehyde, $A O P P$ advanced oxidation protein products, $H D L$ high-density lipoprotein cholesterol, PON1 paraoxonase 1

MDD, and MDD + GAD. Figure 4 shows the biomarkers in these six study groups. Multivariate GLM analysis (with sex, BMI, TUD, age, and education as extraneous variables) showed that there was a significant effect of diagnosis $(F=2.04, \mathrm{df}=35 / 565, p<0.001$; partial eta squared $=0.112$ ) with highly significant between-subject effects on all scores, except $z \mathrm{CAT}+\mathrm{GSH}$ and uric acid. Post-hoc analyses (at $p<0.05)$ indicate that patients with comorbid MDD + GAD have significantly higher zSOD +
$\mathrm{LOOH}, \quad z \mathrm{SOD}+\mathrm{LOOH}+\mathrm{NOx}, \quad z(z \mathrm{SOD}+z \mathrm{LOOH}+$ $z \mathrm{NOx})+z \mathrm{MDA}, \quad z(z \mathrm{SOD}+z \mathrm{LOOH}+z \mathrm{NOx})+z \mathrm{AOPP}$, $z(z \mathrm{SOD}+z \mathrm{LOOH}+z \mathrm{NOx})+z(\mathrm{MDA}+\mathrm{AOPP})$ values as compared with the other five study groups. Figure 4 shows that when GAD is present, these nitro-oxidative indices are higher than in subjects without GAD. Participants with MDD + GAD show more profound aberrations in these indices as compared with the other five study groups. 
Table 3 Estimated marginal mean (SE) values (expressed in $z$ values) obtained by GLM analysis no. 1 in Table 2

\begin{tabular}{|c|c|c|c|}
\hline \multicolumn{2}{|l|}{ Variables } & \multirow{2}{*}{$\begin{array}{l}\text { No GAD } \\
-0.110(0.113)\end{array}$} & \multirow{2}{*}{$\frac{\text { GAD }}{+0.309(0.162)}$} \\
\hline SOD1 & & & \\
\hline $\mathrm{LOOH}$ & & $-0.071(0.108)$ & $+0.313(0.155)$ \\
\hline NOx & & $-0.105(0.11)$ & $+0.505(0.169)$ \\
\hline PON1 & & $+0.211(0.121)$ & $-0.327(0.74)$ \\
\hline HDL & & $+0.003(0.111)$ & $-0.404(0.160)$ \\
\hline Uric acid & & $+0.006(0.100)$ & $+0.563(0.144)$ \\
\hline Variables & & No GAD & GAD \\
\hline NOx & No TUD & $-0.288(0.179)$ & $+0.895(0.266)$ \\
\hline NOx & TUD & $+0.078(0.143)$ & $+0.114(0.203)$ \\
\hline MDA & No TUD & $-0.302(0.165)$ & $+0.288(0.243)$ \\
\hline MDA & TUD & $+0.324(0.133)$ & $+0.126(0.193)$ \\
\hline Uric acid & No TUD & $-0.004(0.152)$ & $+0.891(0.227)$ \\
\hline Uric acid & TUD & $+0.016(0.123)$ & $+0.235(0.174)$ \\
\hline Variables & & No TUD & TUD \\
\hline SOD1 & & $-0.140(0.160)$ & $+0.339(0.124)$ \\
\hline $\mathrm{LOOH}$ & & $-0.141(0.153)$ & $+0.382(0.118)$ \\
\hline PON1 & & $+0.191(0.172)$ & $-0.307(0.133)$ \\
\hline HDL & & $+0.021(0.158)$ & $-0.422(0.122)$ \\
\hline Variables & & Females & Males \\
\hline CAT & & $+0.138(0.110)$ & $-0.312(0.177)$ \\
\hline $\mathrm{LOOH}$ & & $-0.106(0.099)$ & $+0.348(0.158)$ \\
\hline AOPP & & $-0.227(0.103)$ & $+0.673(0.165)$ \\
\hline HDL & & $+0.033(0.102)$ & $-0.434(0.163)$ \\
\hline Uric acid & & $-0.208(0.092)$ & $+0.777(0.147)$ \\
\hline
\end{tabular}

$G A D$ generalized anxiety disorder, $T U D$ tobacco use disorder, $S O D$ superoxide dismutase, $C A T$ catalase, $L O O H$ lipid hydroperoxides, $N O x$ nitric oxide metabolites, $M D A$ malondialdehyde, $A O P P$ advanced oxidation protein products, $H D L$ high-density lipoprotein cholesterol, PON1 paraoxonase 1

A similar GLM analysis performed on the 9 O\&NS biomarkers (see Fig. 5 for the unadjusted means in $z$ transformation) shows that diagnosis has a significant effect $(F=1.90$, $\mathrm{df}=50 / 545, p<0.001$, partial eta-squared $=0.143)$ and that SOD1 is significantly increased in MDD + GAD versus all other study groups (protected post-hoc analyses at $p<0.05$ ).

\section{Effects of Extraneous and Confounding Variables}

Table 2, regression no. 1, shows that TUD, mood disorders, sex, BMI, and education have significant effects on the 10 biomarkers. Age was not significant in the multivariate GLM analysis no. 1 of Table $2(F=1.06, \mathrm{df}=10 / 106, p=$ 0.396). Tests for between-subject effects show that TUD has a significant effect on SOD1, LOOH, PON1 and HDL-cholesterol. The model-generated estimated marginal means in Table 3 show that SOD1 and LOOH are higher, and PON1 and HDL-cholesterol are lower in individuals with TUD as compared with those without TUD.

Tables 2 and 3 show significant effects of sex on LOOH, AOPP, and uric acid (higher in males) and CAT and HDLcholesterol (higher in females). Table 2 shows also a high impact of BMI with a partial eta squared of 0.270. Tests for between-subject effects and parameter estimates show that BMI was significantly and positively associated with uric acid $(F=17.39, \mathrm{df}=1 / 114, p<0.001 ;$ partial eta squared $=0.130)$ and negatively with HDL-cholesterol $(F=17.83, \mathrm{df}=1 / 114$, $p<0.001$; partial eta squared $=0.133$ ). Tests for betweensubject effects and parameter estimates show that years of education is significantly associated with SOD1 (inversely), CAT (positively), and MDA (inversely). There was also a significant effect of mood disorders on the O\&NS biomarkers. However, these data will be presented in another paper on differences among BD and MDD.

We have also adjusted the results for treatment with psychotropic medications and use of alcohol and hypnotics. Thus, treatment with lithium $(F=1.63, \mathrm{df}=10 / 98, p=0.109)$, mood stabilizers $(F=0.70, \mathrm{df}=10 / 98)$, atypical antipsychotics $(F=$ $0.60, \mathrm{df}=10 / 99, p=0.808)$, and use of alcohol $(F=1.30, \mathrm{df}=$ $10 / 105, p=0.238)$ and hypnotics $(F=0.51, \mathrm{df}=10 / 105, p=$ 0.880 ) was not associated with O\&NS biomarkers and did not change the results shown in Table 2 . Nevertheless, there was a very modest but significant effect of antidepressants $(F=1.94$, $\mathrm{df}=10 / 99, p=0.048)$ although tests for between-subject effects showed only a significant effect on GSH values $(F=$ $5.40, \mathrm{df}=1 / 108, p=0.048$, with lower levels in subjects using antidepressants than in those without, i.e., mean $( \pm \mathrm{SD}) z$ values were $-0.359( \pm 0.207)$ versus $0.193( \pm 0.142)$.

A similar pattern of associations was found between the composite scores and the confounder variables: TUD, GAD $\times$ TUD, sex, BMI, and education, were significant in predicting the composite scores. Subjects with TUD showed significantly higher values of different composite score as compared to non-TUD subjects, namely $z \mathrm{SOD}+\mathrm{LOOH}$ $(F=13.69, \mathrm{df}=1 / 116, p<0.001 ;$ partial eta squared $=$ $0.105), z \mathrm{SOD}+\mathrm{LOOH}+\mathrm{NOx}(F=6.72, \mathrm{df}=1 / 116, p=$ 0.011 ; partial eta squared $=0.055), z(z \mathrm{SOD}+z \mathrm{LOOH}+$ $z \mathrm{NOx})+z \mathrm{MDA}(F=7.66, \mathrm{df}=1 / 116, p=0.008$; partial eta squared $=0.060), z(z \mathrm{SOD}+z \mathrm{LOOH}+z \mathrm{NOx})+z \mathrm{AOPP}(F=$ $5.51, \mathrm{df}=1 / 116, p=0.021$; partial eta squared $=0.045)$, $z(z \mathrm{SOD}+z \mathrm{LOOH}+z \mathrm{NOx})+z(\mathrm{MDA}+\mathrm{AOPP})(F=7.20$, $\mathrm{df}=1 / 116, p=0.008$; partial eta squared $=0.058), z$ sum5OX $-z \operatorname{sum} 4$ ANTIOX $(F=5.82, \mathrm{df}=1 / 116, p=0.017$; partial eta squared $=0.098)$, while $z \mathrm{HDL}+\mathrm{PON} 1$ is significantly lower $(F=8.22, \mathrm{df}=1 / 116, p=0.005 ;$ partial eta squared $=0.066)$ in those with TUD. Also, the GAD $\times$ TUD interaction was significant and showed significantly higher $z(\mathrm{SOD}+z \mathrm{LOOH}+$ $z \mathrm{NOx})+z \mathrm{MDA}, z(z \mathrm{SOD}+z \mathrm{LOOH}+z \mathrm{NOx})+z \mathrm{AOPP}$, and $z$ sum5OX $-z$ sum4ANTIOX values in GAD subjects than in those without GAD but only in subject without TUD and not 
Table 4 Results of multivariate general linear model (GLM) analysis with the oxidative and nitrosative stress composite scores as dependent variables and diagnoses as explanatory variables, while controlling for age, sex, body mass index (BMI), education, and tobacco use disorder (TUD)

\begin{tabular}{|c|c|c|c|c|c|c|}
\hline Type test & Dependent variables & Explanatory variables & $F$ & $\mathrm{df}$ & $p$ & Partial eta squared \\
\hline \multirow[t]{7}{*}{ Multivariate $\neq 1$} & \multirow[t]{7}{*}{ All composite scores } & GAD & 5.66 & $7 / 110$ & $<0.001$ & 0.265 \\
\hline & & GAD $\times$ TUD & 3.27 & $7 / 110$ & 0.003 & 0.172 \\
\hline & & $\mathrm{HC} / \mathrm{BD} / \mathrm{MDD}$ & 2.23 & $7 / 110$ & 0.008 & 0.123 \\
\hline & & TUD & 3.46 & $7 / 110$ & 0.002 & 0.181 \\
\hline & & Sex & 8.45 & $7 / 110$ & $<0.001$ & 0.350 \\
\hline & & BMI & 3.78 & $7 / 110$ & 0.001 & 0.194 \\
\hline & & Education & 2.20 & $7 / 110$ & 0.039 & 0.123 \\
\hline \multirow{8}{*}{ Between-subject effects } & $z \mathrm{SOD}+\mathrm{LOOH}$ & GAD & 9.74 & $1 / 116$ & 0.002 & 0.077 \\
\hline & $z \mathrm{SOD}+\mathrm{LOOH}+\mathrm{NOx}$ & GAD & 23.64 & $1 / 116$ & $<0.001$ & 0.169 \\
\hline & $z(z \mathrm{SOD}+z \mathrm{LOOH}+z \mathrm{NOx})+z \mathrm{MDA}$ & GAD & 15.76 & $1 / 116$ & $<0.001$ & 0.120 \\
\hline & $z(z \mathrm{SOD}+z \mathrm{LOOH}+z \mathrm{NOx})+z \mathrm{AOPP}$ & GAD & 16.92 & $1 / 116$ & $<0.001$ & 0.127 \\
\hline & $z(z \mathrm{SOD}+z \mathrm{LOOH}+z \mathrm{NOx})+z(\mathrm{MDA}+\mathrm{AOPP})$ & GAD & 15.56 & $1 / 116$ & $<0.001$ & 0.118 \\
\hline & $z \mathrm{HDL}+\mathrm{PON} 1$ & GAD & 8.62 & $1 / 116$ & 0.004 & 0.069 \\
\hline & $z \mathrm{UA}$ & GAD & 11.05 & $1 / 116$ & 0.001 & 0.087 \\
\hline & $z$ sum5OX $-z$ sum4ANTIOX & GAD & 17.91 & $1 / 116$ & $<0.001$ & 0.134 \\
\hline \multirow[t]{4}{*}{ Between-subject effects } & $z(z \mathrm{SOD}+z \mathrm{LOOH}+z \mathrm{NOx})+z \mathrm{MDA}$ & $\mathrm{GAD} \times \mathrm{TUD}$ & 7.59 & $1 / 116$ & 0.007 & 0.061 \\
\hline & $z(z \mathrm{SOD}+z \mathrm{LOOH}+z \mathrm{NOx})+z(\mathrm{MDA}+\mathrm{AOPP})$ & GAD $\times$ TUD & 5.41 & $1 / 116$ & 0.022 & 0.045 \\
\hline & $z \mathrm{UA}$ & GAD $\times$ TUD & 4.23 & $1 / 116$ & 0.042 & 0.035 \\
\hline & $z \operatorname{sum} 5 \mathrm{OX}-z \operatorname{sum} 4 \mathrm{ANTIOX}$ & GAD $\times$ TUD & 9.87 & $1 / 116$ & 0.002 & 0.078 \\
\hline \multirow[t]{4}{*}{ Between-subject effects } & $z \mathrm{SOD}+\mathrm{LOOH}$ & $\mathrm{HC} / \mathrm{BD} / \mathrm{MDD}$ & 5.44 & $1 / 116$ & 0.006 & 0.086 \\
\hline & $z \mathrm{SOD}+\mathrm{LOOH}+\mathrm{NOx}$ & $\mathrm{HC} / \mathrm{BD} / \mathrm{MDD}$ & 7.67 & $1 / 116$ & 0.001 & 0.117 \\
\hline & $z(z \mathrm{SOD}+z \mathrm{LOOH}+z \mathrm{NOx})+z \mathrm{MDA}$ & $\mathrm{HC} / \mathrm{BD} / \mathrm{MDD}$ & 7.50 & $1 / 116$ & 0.001 & 0.115 \\
\hline & $z(z \mathrm{SOD}+z \mathrm{LOOH}+z \mathrm{NOx})+z(\mathrm{MDA}+\mathrm{AOPP})$ & $\mathrm{HC} / \mathrm{BD} / \mathrm{MDD}$ & 3.74 & $1 / 116$ & 0.027 & 0.061 \\
\hline \multirow[t]{7}{*}{ Between-subject effects } & $z \mathrm{SOD}+\mathrm{LOOH}$ & TUD & 13.65 & $1 / 116$ & $<0.001$ & 0.105 \\
\hline & $z \mathrm{SOD}+\mathrm{LOOH}+\mathrm{NOx}$ & TUD & 6.73 & $1 / 116$ & 0.011 & 0.055 \\
\hline & $z(z \mathrm{SOD}+z \mathrm{LOOH}+z \mathrm{NOx})+z \mathrm{MDA}$ & TUD & 7.36 & $1 / 116$ & 0.008 & 0.060 \\
\hline & $z(z \mathrm{SOD}+z \mathrm{LOOH}+z \mathrm{NOx})+z \mathrm{AOPP}$ & TUD & 5.51 & $1 / 116$ & 0.021 & 0.045 \\
\hline & $z(z \mathrm{SOD}+z \mathrm{LOOH}+z \mathrm{NOx})+z(\mathrm{MDA}+\mathrm{AOPP})$ & TUD & 7.20 & $1 / 116$ & 0.008 & 0.058 \\
\hline & $z \mathrm{HDL}+\mathrm{PON} 1$ & TUD & 8.22 & $1 / 116$ & 0.005 & 0.066 \\
\hline & $z$ sum5OX $-z$ sum4ANTIOX & TUD & 5.82 & $1 / 116$ & 0.017 & 0.048 \\
\hline \multirow[t]{7}{*}{ Between-subject effects } & $z \mathrm{SOD}+\mathrm{LOOH}$ & Sex & 5.63 & $1 / 116$ & 0.019 & 0.046 \\
\hline & $z \mathrm{SOD}+\mathrm{LOOH}+\mathrm{NOx}$ & Sex & 9.32 & $1 / 116$ & 0.003 & 0.074 \\
\hline & $z(z \mathrm{SOD}+z \mathrm{LOOH}+z \mathrm{NOx})+z \mathrm{MDA}$ & Sex & 6.83 & $1 / 116$ & 0.010 & 0.056 \\
\hline & $z(z \mathrm{SOD}+z \mathrm{LOOH}+z \mathrm{NOx})+z \mathrm{AOPP}$ & Sex & 29.48 & $1 / 116$ & $<0.001$ & 0.203 \\
\hline & $z(z \mathrm{SOD}+z \mathrm{LOOH}+z \mathrm{NOx})+z(\mathrm{MDA}+\mathrm{AOPP})$ & Sex & 23.80 & $1 / 116$ & $<0.001$ & 0.170 \\
\hline & $z \mathrm{UA}$ & Sex & 36.35 & $1 / 116$ & $<0.001$ & 0.239 \\
\hline & $z \operatorname{sum} 5 \mathrm{OX}-z$ sum4ANTIOX & Sex & 21.33 & $1 / 116$ & $<0.001$ & 0.155 \\
\hline \multirow[t]{4}{*}{ Between-subject effects } & $z(z \mathrm{SOD}+z \mathrm{LOOH}+z \mathrm{NOx})+z \mathrm{AOPP}$ & BMI & 4.09 & $1 / 116$ & 0.045 & 0.034 \\
\hline & $z(z \mathrm{SOD}+z \mathrm{LOOH}+z \mathrm{NOx})+z(\mathrm{MDA}+\mathrm{AOPP})$ & BMI & 4.26 & $1 / 116$ & 0.041 & 0.035 \\
\hline & $z \mathrm{HDL}+\mathrm{PON} 1$ & BMI & 7.27 & $1 / 116$ & 0.008 & 0.059 \\
\hline & $z \mathrm{UA}$ & BMI & 17.39 & $1 / 116$ & $<0.001$ & 0.130 \\
\hline \multirow[t]{2}{*}{ Between-subject effects } & $z \mathrm{SOD}+\mathrm{LOOH}$ & Education & 6.12 & $1 / 116$ & 0.015 & 0.050 \\
\hline & $(z \mathrm{SOD}+z \mathrm{LOOH}+z \mathrm{NOx})+z \mathrm{MDA}$ & Education & 5.93 & $1 / 116$ & 0.016 & 0.049 \\
\hline \multirow[t]{3}{*}{ Multivariate $\neq 2$} & All composite scores & GAD & 4.76 & $7 / 100$ & $<0.001$ & 0.250 \\
\hline & & $\mathrm{GAD} \times \mathrm{TUD}$ & 3.35 & $7 / 100$ & 0.003 & 0.190 \\
\hline & & HAM-A & 1.18 & $7 / 100$ & 0.323 & 0.076 \\
\hline \multirow[t]{4}{*}{ Multivariate $\neq 3$} & All composite scores & GAD & 5.35 & $7 / 108$ & $<0.001$ & 0.257 \\
\hline & & $\mathrm{GAD} \times \mathrm{TUD}$ & 3.16 & $7 / 108$ & 0.004 & 0.170 \\
\hline & & HAM-D & 3.45 & $7 / 108$ & 0.002 & 0.183 \\
\hline & & YMRS & 0.64 & $7 / 108$ & 0.721 & 0.040 \\
\hline
\end{tabular}

$G A D$ generalized anxiety disorder, $H C / B D / M D D$ healthy controls/bipolar disorder/major depression, $H A M-A$ Hamilton Anxiety Rating Scale score, $H A M-D$ Hamilton Depression Rating Scale score, YMRS Young Mania Rating Scale, SOD superoxide dismutase, CAT catalase, $L O O H$ lipid hydroperoxides, $N O x$ nitric oxide metabolites, $M D A$ malondialdehyde, $A O P P$ advanced oxidation protein products, $U A$ uric acid, GSH glutathione, $H D L$ highdensity lipoprotein cholesterol, $P O N 1$ paraoxonase 1

$z \mathrm{SOD}+\mathrm{LOOH}$ : computed as $z$ transformed value of $\mathrm{SOD}(z \mathrm{SOD})+z \mathrm{LOOH}$

$z \mathrm{SOD}+\mathrm{LOOH}+\mathrm{NOx}: z \mathrm{SOD}+z \mathrm{LOOH}+z \mathrm{NOx}$

$z(z \mathrm{SOD}+z \mathrm{LOOH}+z \mathrm{NOx})+z \mathrm{MDA}:$ computed as $z(z \mathrm{SOD}+z \mathrm{LOOH}+z \mathrm{NOx})+z \mathrm{MDA}$

$z(z \mathrm{SOD}+z \mathrm{LOOH}+z \mathrm{NOx})+z \mathrm{AOPP}:$ computed as $z(z \mathrm{SOD}+z \mathrm{LOOH}+z \mathrm{NOx})+z \mathrm{AOPP}$

$z(z \mathrm{SOD}+z \mathrm{LOOH}+z \mathrm{NOx})+z(\mathrm{MDA}+\mathrm{AOPP}):$ computed as $z(z \mathrm{SOD}+z \mathrm{LOOH}+z \mathrm{NOx})+z(\mathrm{MDA}+\mathrm{AOPP})$

$z \mathrm{HDL}+\mathrm{PON} 1$ : computed as $z \mathrm{HDL}-$ cholesterol $+z \mathrm{PON} 1$

$z \mathrm{UA}: z$ uric acid

$z \operatorname{sum} 5 \mathrm{OX}-z \operatorname{sum} 4 \mathrm{ANTIOX}$ : computed as $z(z \mathrm{SOD}+z \mathrm{LOOH}+z \mathrm{NOx}+z \mathrm{MDA}+z \mathrm{AOPP})-z(z \mathrm{HDL}-\mathrm{cholesterol}+z \mathrm{PON} 1+z \mathrm{GSH}+z \mathrm{CAT})$ 
Table 5 Estimated marginal mean (SE) values (expressed in $z$ values) obtained by GLM analysis no. 1 in Table 4

\begin{tabular}{|c|c|c|c|}
\hline \multicolumn{2}{|l|}{ Variables } & No GAD & GAD \\
\hline \multicolumn{2}{|l|}{$z \mathrm{SOD}+\mathrm{LOOH}$} & $-0.122(0.102)$ & $+0.407(0.1465)$ \\
\hline \multicolumn{2}{|l|}{$z \mathrm{SOD}+\mathrm{LOOH}+\mathrm{NOx}$} & $-0.140(0.0 .096)$ & $+0.639(0.138)$ \\
\hline \multicolumn{2}{|l|}{$z(z \mathrm{SOD}+z \mathrm{LOOH}+z \mathrm{NOx})+z \mathrm{MDA}$} & $-0.085(0.094)$ & $+0.535(0.0 .134)$ \\
\hline \multicolumn{2}{|l|}{$z(z \mathrm{SOD}+z \mathrm{LOOH}+z \mathrm{NOx})+z \mathrm{AOPP}$} & $-0.040(0.099)$ & $+0.639(0.142)$ \\
\hline \multicolumn{2}{|c|}{$z(z \mathrm{SOD}+z \mathrm{LOOH}+z \mathrm{NOx})+z(\mathrm{MDA}+\mathrm{AOPP})$} & $-0.030(0.096)$ & $+0.604(0.138)$ \\
\hline \multicolumn{2}{|l|}{$z \mathrm{HDL}+\mathrm{PON} 1$} & $+0.187(0.185)$ & $-0.718(0.265)$ \\
\hline \multicolumn{2}{|l|}{$z \operatorname{sum} 5 \mathrm{OX}-z \operatorname{sum} 4 \mathrm{ANTIOX}$} & $-0.050(0.098)$ & $+0.644(0.141)$ \\
\hline$z(z \mathrm{SOD}+z \mathrm{LOOH}+z \mathrm{NOx})+z \mathrm{MDA}$ & No TUD & $-0.519(0.142)$ & $+0.349(0.114)$ \\
\hline$z(z \mathrm{SOD}+z \mathrm{LOOH}+z \mathrm{NOx})+z \mathrm{MDA}$ & TUD & $+0.523(0.211)$ & $+0.548(0.162)$ \\
\hline$z(z \mathrm{SOD}+z \mathrm{LOOH}+z \mathrm{NOx})+z \mathrm{AOPP}$ & No TUD & $-0.358(0.150)$ & $+0.279(0.121)$ \\
\hline$z(z \mathrm{SOD}+z \mathrm{LOOH}+z \mathrm{NOx})+z \mathrm{AOPP}$ & TUD & $+0.550(0.223)$ & $+0.728(0.171)$ \\
\hline$z \operatorname{sum} 5 \mathrm{OX}-z$ sum4ANTIOX & No TUD & $-0.511(0.149)$ & $+0.411(0.120)$ \\
\hline$z \operatorname{sum} 5 \mathrm{OX}-z$ sum4ANTIOX & TUD & $+0.688(0.222)$ & $+0.600(0.170)$ \\
\hline
\end{tabular}

GAD generalized anxiety disorder, TUD tobacco use disorder, $S O D$ superoxide dismutase, $C A T$ catalase, $L O O H$ lipid hydroperoxides, $N O x$ nitric oxide metabolites, $M D A$ malondialdehyde, $A O P P$ advanced oxidation protein products, $G S H$ glutathione, $H D L$ high-density lipoprotein cholesterol, $P O N 1$ paraoxonase 1

$z(z \mathrm{SOD}+z \mathrm{LOOH}+z \mathrm{NOx})+z \mathrm{MDA}:$ computed as $z(z \mathrm{SOD}+z \mathrm{LOOH}+z \mathrm{NOx})+z \mathrm{MDA}$

$z(z \mathrm{SOD}+z \mathrm{LOOH}+z \mathrm{NOx})+z \mathrm{AOPP}:$ computed as $z(z \mathrm{SOD}+z \mathrm{LOOH}+z \mathrm{NOx})+z \mathrm{AOPP}$

$z$ sum $5 \mathrm{OX}-z$ sum 4 ANTIOX: computed as $z(z \mathrm{SOD}+z \mathrm{LOOH}+z \mathrm{NOx}+z \mathrm{MDA}+z \mathrm{AOPP})-z(z \mathrm{HDL}-\mathrm{cholester}-$ $\mathrm{ol}+z \mathrm{PON} 1+z \mathrm{GSH}+z \mathrm{CAT})$

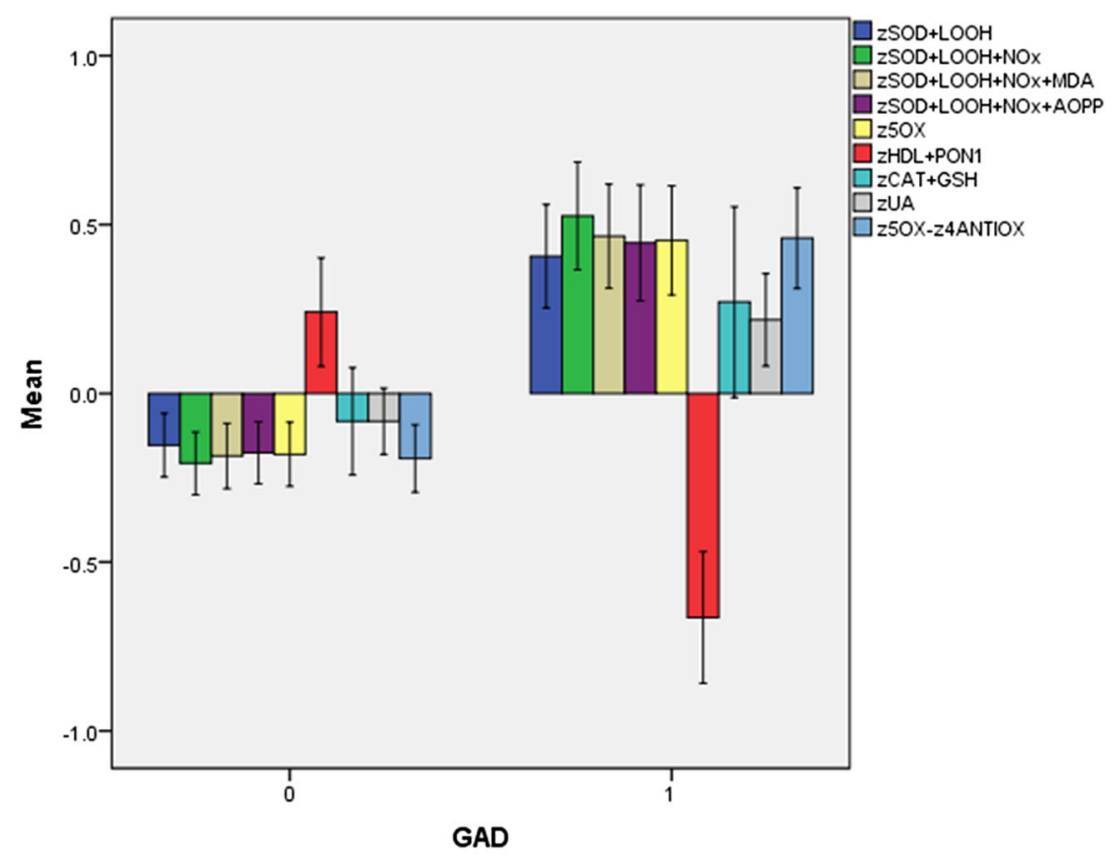

Error bars: $+/ 1 \mathrm{SE}$

Fig. 3 Measurements (in $z$-transformations) of nitro-oxidative stress indices in participants with (1) and without (0) generalized anxiety disorder. SOD superoxide dismutase, CAT catalase, LOOH lipid hydroperoxides, NOx nitric oxide metabolites, MDA malondialdehyde, AOPP advanced oxidation protein products, GSH glutathione, UA uric acid, HDL high-density lipoprotein cholesterol, PON1 paraoxonase 1. $z \mathrm{SOD}+\mathrm{LOOH}$ : computed as $z$ transformed value of SOD $(z \mathrm{SOD})+$ zLOOH. $z \mathrm{SOD}+\mathrm{LOOH}+\mathrm{NOx}: z \mathrm{SOD}+z \mathrm{LOOH}+z \mathrm{NOx} . \quad z \mathrm{SOD}+$
$\mathrm{LOOH}+\mathrm{NOx}+\mathrm{MDA}:$ computed as $z(z \mathrm{SOD}+z \mathrm{LOOH}+z \mathrm{NOx})+$ zMDA. $z \mathrm{SOD}+\mathrm{LOOH}+\mathrm{NOx}+\mathrm{AOPP}:$ computed as $z(z \mathrm{SOD}+$ $z \mathrm{LOOH}+z \mathrm{NOx})+z$ AOPP. $z 5 \mathrm{OX}$ : computed as $z(z \mathrm{SOD}+z \mathrm{LOOH}+$ $z \mathrm{NOx})+z(\mathrm{MDA}+\mathrm{AOPP}) . z \mathrm{HDL}+\mathrm{PON} 1:$ computed as $z \mathrm{HDL}-\mathrm{choles}-$ terol $+z \mathrm{PON} 1 . z \mathrm{CAT}+\mathrm{GSH}:$ computed as $z \mathrm{CAT}+z \mathrm{GSH} . z \mathrm{UA}: z$ uric acid. $z 5 \mathrm{OX}-z 4 \mathrm{ANTIOX}$ : computed as $z(z \mathrm{SOD}+z \mathrm{LOOH}+z \mathrm{NOx}+$ $z \mathrm{MDA}+z \mathrm{AOPP})-z(z \mathrm{HDL}-$ cholesterol $+z \mathrm{PON} 1+z \mathrm{GSH}+z \mathrm{CAT})$ 
Fig. 4 Measurements (in ztransformations) of eight nitrooxidative stress indices in healthy controls (HC), subjects with generalized anxiety disorder (GAD), bipolar disorder (BD), comorbid $\mathrm{BD}$ with GAD (BD + GAD), major depression (MDD), and comorbid MDD with GAD (MDD + GAD). See legends to Fig. 3 for abbreviations

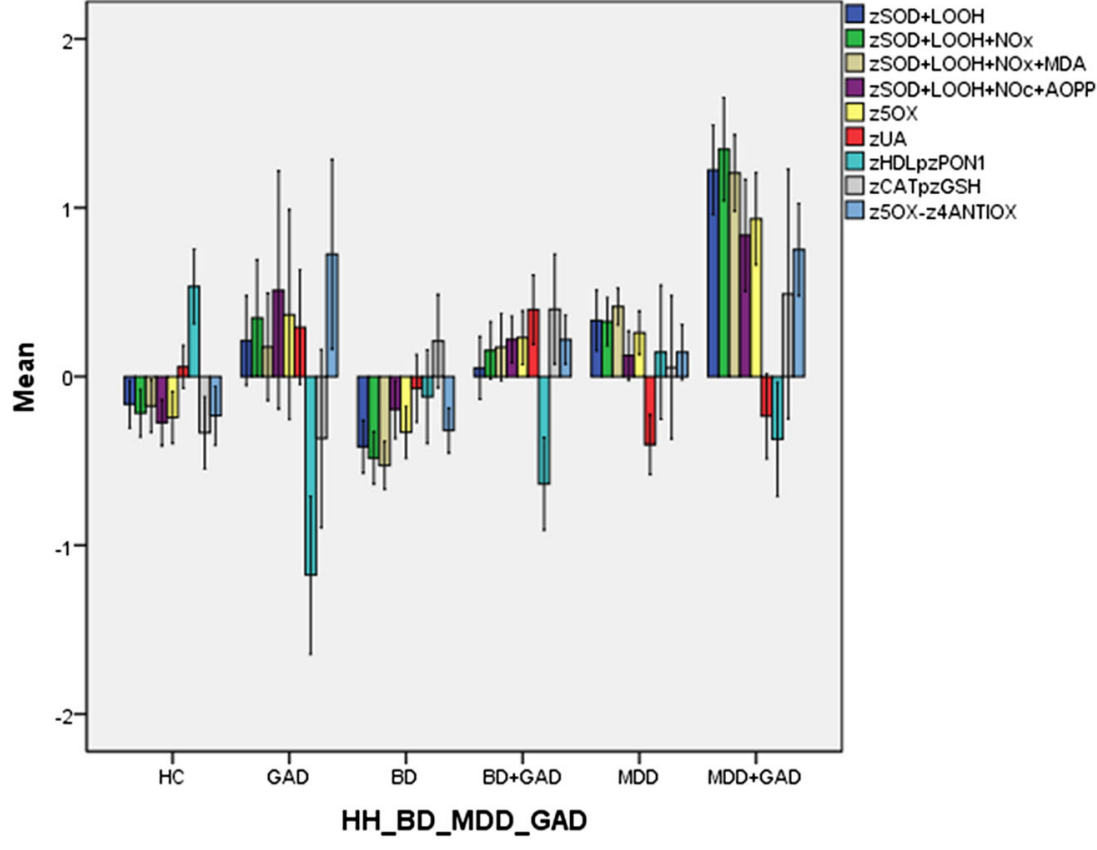

Error bars: +/- $1 \mathrm{SE}$ in those with TUD. Males showed significantly higher values of composite score as compared to females, namely $z \mathrm{SOD}+$ $\mathrm{LOOH}(F=5.63, \mathrm{df}=1 / 116, p=0.019$; partial eta squared $=$ $0.046), z \mathrm{SOD}+\mathrm{LOOH}+\mathrm{NOx}(F=9.32, \mathrm{df}=1 / 116, p=$ 0.003 ; partial eta squared $=0.074), z(z \mathrm{SOD}+z \mathrm{LOOH}+$ $z$ NOx $)+z$ MDA $(F=6.83, \mathrm{df}=1 / 116, p=0.010 ;$ partial eta squared $=0.056), z(z \mathrm{SOD}+z \mathrm{LOOH}+z \mathrm{NOx})+z \mathrm{AOPP}(F=$ $29.48, \mathrm{df}=1 / 116, p<0.001$; partial eta squared $=0.203)$, $z(z \mathrm{SOD}+z \mathrm{LOOH}+z \mathrm{NOx})+z(\mathrm{MDA}+\mathrm{AOPP})(F=23.80$, $\mathrm{df}=1 / 116, p<0.001$; partial eta squared $=0.170), z$ sum5OX
Fig. 5 Measurements (in ztransformations) of superoxide dismutase (SOD), lipid hydroperoxides $(\mathrm{LOOH})$, nitric oxide metabolites (NOx), paraoxonase 1 (resPON), highdensity lipoprotein cholesterol (HDL), and uric acid (UA) in healthy controls $(\mathrm{HC})$, subjects with generalized anxiety disorder (GAD), bipolar disorder (BD), comorbid BD with GAD (BD + GAD), major depression (MDD), and comorbid MDD with GAD (MDD + GAD).

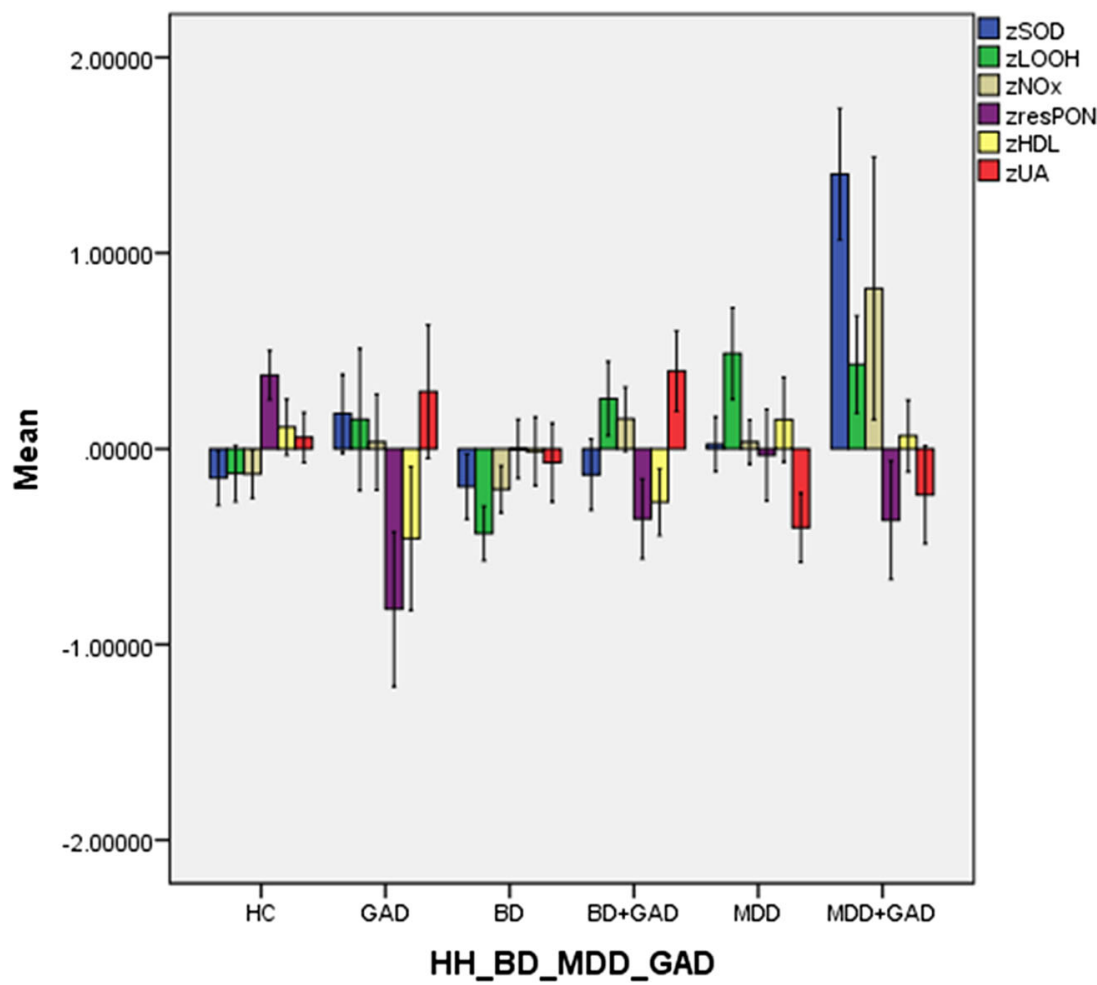

Error bars: +/- 1 SE 
- zsum4ANTIOX $(F=21.33, \mathrm{df}=1 / 116, p<0.001$; partial eta squared $=0.155)$, and uric acid $(F=36.35, \mathrm{df}=1 / 116$, $p<0.001$; partial eta squared $=0.239$ ).

There were significant and positive associations between BMI and composite scores, namely $z(z \mathrm{SOD}+z \mathrm{LOOH}+$ $z \mathrm{NOx})+z$ AOPP $(F=4.09, \mathrm{df}=1 / 116, p=0.045$; partial eta squared $=0.034), z(z \mathrm{SOD}+z \mathrm{LOOH}+z \mathrm{NOx})+z(\mathrm{MDA}+$ AOPP $)(F=4.26, \mathrm{df}=1 / 116, p=0.041$; partial eta squared $=$ $0.035)$, and negative association with $z$ HDL+PON1 $(F=7.27$, $\mathrm{df}=1 / 116, p=0.008$; partial eta squared $=0.059)$. Education was significantly inversely associated with two composite scores, namely $z \mathrm{SOD}+\mathrm{LOOH}(F=6.12, \mathrm{df}=1 / 116, p=$ 0.015 ; partial eta squared $=0.050)$ and $z(z \mathrm{SOD}+z \mathrm{LOOH}+$ $z \mathrm{NOx})+z \mathrm{MDA}(F=5.93, \mathrm{df}=1 / 116, p=0.016$; partial eta squared $=0.049)$.

\section{Best Predictions of O\&NS Biomarkers}

In order to assess the most adequate prediction of GAD, we have carried out binary logistic regression analysis with GAD as dependent variable, no GAD as reference group, and the O\&NS biomarkers, age, sex, TUD, HAM-D, and HAM-A as explanatory variables (Table 6). Using the 10 O\&NS biomarkers, we found that GAD was significantly associated with SOD1, uric acid, and HAM-D (all positively) and with PON1 (inversely); $79.8 \%$ of all cases were correctly classified with a sensitivity of $58.1 \%$ and a specificity of $88.5 \%$. Using the composite scores, we detected that $z(\mathrm{SOD}+\mathrm{LOOH}+\mathrm{NOx})$ and HAM-D (positively) and $z \mathrm{HDL}+\mathrm{PON} 1$ (inversely) were associated with GAD. Using both the 10 measurements and the composite scores showed that $z(\mathrm{SOD}+\mathrm{LOOH}+\mathrm{NOx})+$ zMDA, uric acid and HAM-D (all positively), and PON1 (inversely) were significantly associated with GAD. All participants $(79.8 \%)$ were correctly classified with a sensitivity of $51.6 \%$ and a specificity of $91.0 \%$.

\section{Discussion}

The main finding of this study is that GAD is accompanied by increased SOD1 activity and $\mathrm{LOOH}, \mathrm{NOx}$, and uric acid levels and lowered PON1 activity and HDL-cholesterol levels and by changes in different composite scores indicating increased nitro-oxidative stress with lipid peroxidation and lowered lipid-associated antioxidant defenses. These findings extend those of previous reports showing that individuals with GAD have a higher total antioxidant status and oxidative stress index and lower antioxidant levels (Emhan et al. 2015; Ercan et al. 2017). Our results that LOOH is increased in GAD corroborate the study by Bulut et al. (2013), but the findings on lowered PON1 activity do not. PON1 activity may be determined using different substrates, and the rate of hydrolysis of some substrates is influenced by the PON1 Q192R polymorphisms. Because of this, it is strongly recommended that PON1 total plasmatic activity be determined using phenyl acetate, a substrate which hydrolysis is not influenced by the Q192R polymorphism (Billecke and Teiber 2011; Jarvik et al. 2000). Differently from our results, Bulut et al. (2013) did not find decreased PON1 total plasmatic activity (named AREase activity by the authors) but reported decreased activity against

Table 6 Results of binary regression analyses with generalized anxiety disorder (GAD) as dependent variable and nitro-oxidative biomarkers, demographic, and clinical data as explanatory variables

\begin{tabular}{|c|c|c|c|c|c|c|c|}
\hline Regression & $\begin{array}{l}\text { Nagelkerke } \\
\text { Overall } \chi^{2}, \mathrm{df}, p\end{array}$ & Explanatory variables & Wald & $\mathrm{df}$ & $p$ & OR & $95 \% \mathrm{CI}$ \\
\hline Regression no. 1 & $\begin{array}{l}0.463 \\
\chi^{2}=48.03, \mathrm{df}=2, p<0.001\end{array}$ & $\begin{array}{l}\text { SOD1 } \\
\text { PON1 } \\
\text { Uric acid } \\
\text { HAM-D }\end{array}$ & $\begin{array}{l}10.76 \\
7.15 \\
5.85 \\
11.65\end{array}$ & $\begin{array}{l}1 \\
1 \\
1 \\
1\end{array}$ & $\begin{array}{l}0.001 \\
0.008 \\
0.016 \\
0.001\end{array}$ & $\begin{array}{l}2.45 \\
0.42 \\
2.02 \\
1.15\end{array}$ & $\begin{array}{l}1.43-4.19 \\
0.22-0.79 \\
1.14-3.56 \\
1.06-1.24\end{array}$ \\
\hline Regression no. 2 & $\begin{array}{l}0.371 \\
\chi^{2}=32.66, \mathrm{df}=3, p<0.001\end{array}$ & $\begin{array}{l}z \mathrm{SOD}+\mathrm{LOOH}+\mathrm{NOx} \\
z \mathrm{HDL}+\mathrm{PON} 1 \\
\mathrm{HAM}-\mathrm{D}\end{array}$ & $\begin{array}{l}10.41 \\
4.41 \\
9.62\end{array}$ & $\begin{array}{l}1 \\
1 \\
1\end{array}$ & $\begin{array}{l}0.001 \\
0.036 \\
0.002\end{array}$ & $\begin{array}{l}2.77 \\
0.67 \\
1.13\end{array}$ & $\begin{array}{l}1.49-5.13 \\
0.46-0.97 \\
1.05-1.12\end{array}$ \\
\hline Regression no. 3 & $\begin{array}{l}0.437 \\
\chi^{2}=39.63, \mathrm{df}=4, p<0.001\end{array}$ & $\begin{array}{l}z(\mathrm{SOD}+\mathrm{LOOH}+\mathrm{NOx})+z \mathrm{MDA} \\
\text { PON1 } \\
\text { Uric acid } \\
\text { HAM-D }\end{array}$ & $\begin{array}{l}10.71 \\
7.66 \\
4.23 \\
14.57\end{array}$ & $\begin{array}{l}1 \\
1 \\
1 \\
1\end{array}$ & $\begin{array}{l}0.001 \\
0.006 \\
0.040 \\
<0.001\end{array}$ & $\begin{array}{l}3.15 \\
0.38 \\
1.84 \\
1.20\end{array}$ & $\begin{array}{l}1.58-6.25 \\
0.19-0.75 \\
1.03-3.28 \\
1.09-1.31\end{array}$ \\
\hline
\end{tabular}

OR odds ratio, 95\% CI 95\% confidence intervals, SOD1 superoxide dismutase, PON1 paraoxonase1, HAM-D Hamilton Depression Rating Scale score $z \mathrm{SOD}+\mathrm{LOOH}$ : computed as $z$ transformed value of SOD $(z \mathrm{SOD})+z \mathrm{LOOH}$

$z \mathrm{SOD}+\mathrm{LOOH}+\mathrm{NOx}: z \mathrm{SOD}+z \mathrm{LOOH}+z \mathrm{NOx}$

$z(z \mathrm{SOD}+z \mathrm{LOOH}+z \mathrm{NOx})+z \mathrm{MDA}:$ computed as $z(z \mathrm{SOD}+z \mathrm{LOOH}+z \mathrm{NOx})+z \mathrm{MDA}$

$z \mathrm{HDL}+\mathrm{PON} 1:$ computed as $z \mathrm{HDL}-$ cholesterol $+z \mathrm{PON} 1$ 
paraoxon (named paraoxonase activity by the authors), a substrate that is influenced by the polymorphism and must be adjusted by the PON Q192R genotype.

In addition, our study found higher SOD1 activity and no significant changes in catalase activity between participants with and without GAD. SOD1 is an antioxidant enzyme that protects against the moderately reactive superoxide radicals and catalyzes the partition of superoxide radicals into oxygen and hydrogen peroxides (Fukai and Ushio-Fukai 2011; McCord and Edeas 2005). Catalase and GPx may further degrade peroxides into $\mathrm{H}_{2} \mathrm{O}$ but when $\mathrm{Fe}++$ ions (or heavy metals) are present, peroxides are converted to the very reactive hydroxyl radicals, which may damage lipids, proteins, and DNA (Fukai and Ushio-Fukai 2011; McCord and Edeas 2005). Therefore, our results that SOD1 and LOOH levels are increased in GAD, without changes in catalase, indicate that GAD is accompanied by elevated hydroxyl radical production, which in part may be explained by enhanced SOD1 activity. Increased generation of hydroxyl radicals may cause lipid peroxidation (formation of $\mathrm{LOOH}$ ) from unsaturated phospholipids and cholesterol (Girotti 1998). Thus, while SOD1 protects against the effects of increased superoxide radicals through the dismutation of superoxide radicals, SOD is a major source of hydrogen peroxide production (Fukai and Ushio-Fukai 2011; McCord and Edeas 2005; Hayyan et al. 2016). The latter may lead, depending on the activity of catalase and GPx and $\mathrm{Fe}^{2+}$ levels, to increased production of more reactive hydroxyl radicals and consequently lipid peroxidation. Some data, however, suggest that the Fenton reaction may be of minor importance in the production of hydroxyl radicals (Saran et al. 2000). Under stress conditions, however, an excess of "superoxide releases free iron from ironcontaining molecules," which may participate in the Fenton reaction and the production of hydroxyl radicals (Valko et al. 2007). Most importantly, SOD1 overexpression may cause oxidative injuries to cells and even cell death, mediated by elevated production of hydrogen peroxides (Xing et al. 2002). As such, SOD1 may have a triphasic effect: (a) low SOD1 activity increases susceptibility to oxidative stress, (b) moderately increased SOD1 levels have protective effects, and (c) very high SOD1 may cause oxidative damage to cells mediated by increased hydrogen peroxide levels (Xing et al. 2002). All in all, it appears that in GAD, the combination of increased SOD1 and unaltered catalase activity is insufficient to remove oxygen radicals and protect lipids against lipid peroxidation.

Importantly, SOD1 mRNA expression is elevated by nitro-oxidative stress (e.g., nitric oxide and hydrogen peroxides), T cell-mediated mechanisms, endotoxin, and proinflammatory cytokines such as tumor necrosis factor (TNF)- $\alpha$ (Harris 1992; Terrazzano et al. 2014; Zelko et al. 2002; Miao and St Clair 2009; Rojo et al. 2004; Marikovsky et al. 2003). This is important as mood disorders and GAD are characterized by activated immune-inflammatory pathways (Maes 2008; Michopoulos et al. 2017). Therefore, the activated immune-inflammatory processes in those illnesses may play an important role in the SOD1 activation observed in our study. Moreover, increased SOD1 expression may contribute to inflammation by increasing the production of TNF- $\alpha$ and metalloproteinases (Marikovsky et al. 2003), although lowered SOD1 activity yields also proinflammatory effects (Ishigami et al. 2011). Finally, there are many more links between immune and redox systems explaining the tight connection between both systems in mood disorders (Moylan et al. 2014), including increased MPO levels, a major multifunctional player in innate and acquired immunity (Arnhold and Flemmig 2010).

Our study also observed increased NOx levels and an increased composite score SOD + $\mathrm{LOOH}+\mathrm{NOx}$ in GAD, indicating that increased NO production coupled with superoxide radicals has increased the propensity to form peroxynitrite which, in turn, together with hydroxyl radicals may cause lipid peroxidation (Girotti 1998; Pacher et al. 2007). Therefore, the higher values of this composite score in GAD show that this condition is accompanied by increased nitro-oxidative stress (elevated ROS + RNS generation), which has caused lipid peroxidation.

Our study found that GAD is associated not only with lowered PON1 activity, but also with lowered HDLcholesterol concentrations, while GSH and catalase are not significantly altered. In fact, lowered values of the $z$ PON1 + HDL and increased zSOD + $\mathrm{LOOH}+\mathrm{NOx}$ composite scores were the most significant predictors of GAD, suggesting that both increased nitro-oxidative stress and attenuated lipidassociated antioxidant defenses participate in the pathophysiology of GAD. Following PON1 production in the liver, PON1 is secreted into the peripheral blood and is integrated into HDL molecules and then activated during HDL maturation (Gugliucci and Menini 2015; Huang et al. 2013). The anchored PON1, in turn, protects HDL from oxidation by hydrolyzing phospholipid or cholesteryl ester hydroperoxides (Watson et al. 1995). This functional HDL-PON1 binding may explain the significant positive correlations between both molecules found in the present study. Moreover, PON1 activity protects against lipid and LDL oxidation and stimulates the ability of HDL to enhance cholesterol efflux from macrophages (Gugliucci and Menini 2015; Efrat and Aviram 2010). These pathways explain that PON1 protects against macrophage-mediated LDL oxidation thereby displaying antiinflammatory and atheroprotective properties (Mackness and Mackness 2015; Costa et al. 2005). Activated macrophages produce peroxides, NO and MPO, which together may generate peroxynitrite and $\mathrm{HOCl}$. The latter two toxic products may damage PON1 in HDL, while MPO may further oxidize PON1 thereby inactivating PON1 and attenuating its binding to HDL (Gugliucci and Menini 2015). Thus, 
inflammation-associated production of ROS/RNS may downregulate the protective effects of PON1/HDL thereby inducing lipid peroxidation and MDA formation, which may further damage lipids (Gugliucci and Menini 2015). In addition, PON1 may dampen MPO activity and as a consequence lowered PON1 activity may further enhance MPO activity thereby increasing peroxynitrite and hypochlorous acid, which may cause increased AOPP production. These reciprocal interactions between PON1 binding to HDL and ROS/ RNS production explain the significant and inverse correlations found in the present study between lowered $z \mathrm{HDL}+$ PON1 scores and indices of nitro-oxidative stress and damage to lipids and proteins.

Moreover, our results show that GAD may be accompanied by a moderate increase in aldehyde, but not AOPP, production. In nonsmokers, but not in smokers, we found that MDA and the composite score $(\mathrm{SOD}+\mathrm{LOOH}+$ NOx) + MDA were significantly higher in individuals with GAD than in those without. This suggests that the well-known effects of TUD on nitro-oxidative pathways (Nunes et al. 2013) may blur a moderate association between GAD and MDA. MDA is a highly reactive aldehyde, which may damage cells, proteins, and DNA thereby causing inflammatory, genotoxic, and cytotoxic responses (Maes et al. 2011a). Aldehydes are mainly generated by hydroxyl radicals and increased peroxynitrite production contributing to lipid hydroperoxide chain reactions. Increased AOPP formation is the consequence of increased hypochlorous acid stress via increased MPO activity coupled with elevated peroxide production, via SOD and peroxynitrite production (Huang et al. 2013). Phrased differently, GAD appears to be accompanied by relevant increases in ROS/RNS or nitro-oxidative stress, while there are only moderate or no changes in their consequences, namely enhanced aldehyde and AOPP formation. By inference, it appears that patients with GAD have some protection against these consequences of activated nitro-oxidative processes. One explanation is that the formation of hydroxyl radical and peroxynitrite is inhibited by increased levels of uric acid (Regoli and Winston 1999), which is generated by xanthine oxidase together with superoxide and NO radicals (Kuppusamy and Zweier 1989). The latter two radicals, in turn, generate peroxynitrite and hydroxyl radicals, which are scavenged by uric acid with a potency similar to ascorbic acid and Trolox (Regoli and Winston 1999). Therefore, increased uric acid levels may be regarded as a beneficial compensatory mechanism in response to oxidative stress (Soltani et al. 2013). Nevertheless, following reactions with oxidants (including peroxynitrite), uric acid may form reactive intermediates or urate radicals, which are proinflammatory and pro-oxidants thereby contributing to cardiovascular disease, hypertension, and metabolic syndrome
(Gersch et al. 2009; Soltani et al. 2013). Based on this knowledge, it may be suggested that increased xanthine oxidase activity may occur in GAD.

A second major finding is that the co-occurrence between MDD and GAD is characterized by significant additive effects on nitro-oxidative pathways, resulting in more activated pathways in this co-occurrence. Thus, the presence of GAD in major depression signals an increased nitro-oxidative burden in an illness that is already characterized by increased nitrooxidative stress (see Introduction and Figs. 4 and 5). These findings could explain that the co-occurrence of GAD and MDD may predict poorer outcomes than GAD or MDD alone, including effects on quality of life (Zhou et al. 2017). Moreover, our findings may have important consequences for comorbid medical illness in depression and GAD. For example, the high comorbidity between depression and cardiovascular disorder and metabolic syndrome may be explained by increased nitrosative stress, lipid peroxidation, and lowered antioxidant defenses (Maes et al. 2011c; de Melo et al. 2017). There is also a high comorbidity between GAD and cardiovascular disorder (Tully and Cosh 2013; Martens et al. 2010) and metabolic syndrome (Carroll et al. 2009). Thus, activated nitro-oxidative stress pathways combined with lowered antioxidant defenses in GAD and especially in GAD + MDD may explain at least in part the increased co-occurrence between GAD and these medical disorders. Our findings on the biological underpinnings of the comorbidity between anxiety and mood disorders further underscore that psychiatric classifications should be revised based on knowledge from translational neuroscience, especially neuroimmunology (Stoyanov 2017).

A third major finding of this study revolves around severity of depression being associated with O\&NS biomarkers and GAD. Firstly, severity of depression (and to a lesser extent also severity of anxiety) was significantly and independently from diagnoses of GAD and mood disorders associated with LOOH, AOPP, and different composites scores. Thus, it appears that lipid peroxidation and AOPP formation are sensitive to increased severity of depression. Previously, it was shown that in mood disorders various O\&NS biomarkers, including TBARS (Maes et al. 2011a; Sowa-Kućma et al. 2018) and AOPP (Roomruangwong et al. 2017; Gomes et al. 2017) are significantly correlated with severity of depression. Secondly, GAD is strongly associated with severity of depression, but not anxiety. Moreover, there is a strong similarity between the O\&NS profile of GAD established in the current study and the profile established in major depression (Maes et al. 2011a; Liu et al. 2015; Mazereeuw et al. 2015; Andreazza et al. 2008; Brown et al. 2014). Table 7 summarizes the similarities and differences between both disorders based on the current findings and previous literature. Thus, both GAD and depression are accompanied by lowered total PON1 activities and HDL-cholesterol levels, increased SOD 
Table 7 Comparison of nitro-oxidative pathways among patients with depression (previous studies) and generalized anxiety disorder (GAD) (the current study)

\begin{tabular}{lll}
\hline & Depression & GAD \\
\hline Biomarkers & & \\
Superoxide dismutase & $\uparrow$ & $\uparrow$ \\
Peroxides & $\uparrow$ & $?$ \\
Catalase & 0 & 0 \\
Lipid hydroperoxides & $\uparrow$ & $\uparrow$ \\
Nitric oxide metabolites & $\uparrow$ & $\uparrow$ \\
Malondialdehyde & $\uparrow \uparrow$ & $\uparrow$ \\
Advanced oxidation protein products & $\uparrow \uparrow$ & 0 \\
High-density lipoprotein cholesterol & $\downarrow$ & $\downarrow$ \\
Paraoxonase 1 & $\downarrow$ & $\downarrow$ \\
Reduced glutathione & $\downarrow$ & 0 \\
Uric acid & $\downarrow$ & $\uparrow$ \\
Pathways & & \\
Nitro-oxidative stress & $\uparrow \uparrow$ & $\uparrow \uparrow$ \\
Lipid peroxidation & $\uparrow \uparrow$ & $\uparrow \uparrow$ \\
Aldehyde formation & $\uparrow \uparrow$ & $\uparrow \uparrow$ \\
Protein oxidation & $\uparrow \uparrow$ & 0 \\
\hline
\end{tabular}

$\uparrow:$ increased levels or activities, $\downarrow:$ lowered levels or activities, 0 unaltered

activity, lipid peroxidation, NOx levels, and aldehyde formation (TBARS/MDA). Such shared pathways may explain the strong comorbidity between GAD and depression (see the "Introduction" section). There is some evidence that, based on similarities in the areas of demographics, phenomenology, genetics, and childhood environment, GAD shows a strong overlap with mood disorders, especially depression (Mennin et al. 2008; Hettema 2008). Therefore, it was proposed that GAD may belong to the mood disorders spectrum and should be reclassified in the same diagnostic category as major depression (Mennin et al. 2008). Nevertheless, comorbidity, treatment, personality, life events, and biomarker data are more mixed and showed also clear differences (Hettema 2008). Also, the current study showed that GAD was accompanied by increased nitro-oxidative stress and uric acid levels and a moderately increased aldehyde production, but no significant changes in AOPP levels. Mood disorders, on the other hand, are characterized by enhanced nitro-oxidative pathways and highly increased aldehyde and AOPP production, while some papers report lowered uric acid in depression (Maes et al. 2011a; Liu et al. 2015; Mazereeuw et al. 2015; Andreazza et al. 2008; Brown et al. 2014; Gomes et al. 2017; Wen et al. 2012). In fact, higher levels of uric acid may be associated with a lower risk of depression (WiumAndersen et al. 2017). This is interesting given that the current study found that GAD is accompanied by increased uric acid levels. Nevertheless, the hypothesis is that in both GAD and depression uric acid may exert protective effects and that increased levels of uric acid in GAD may perhaps explain why aldehyde production and protein oxidation are less severe in GAD as compared with depression.

The fourth finding of this study is that patients with other anxiety disorders, namely simple and social phobia or panic disorder, do not show significant changes in nitro-oxidative pathways. These findings extend those of Hagan et al. (2015) who could not find associations between phobic anxiety and oxidative stress. Nevertheless, a few reports showed increased pro- and antioxidant levels in social phobia (Atmaca et al. 2004) and increased MDA but lower PON1 activity and GPx-1 and PON1 192AA polymorphisms in panic disorders (Gul et al. 2013; Cengiz et al. 2015; Atasoy et al. 2015). Nevertheless, even in the general population, individuals often have one or more anxiety disorders in a lifetime although they not necessarily co-occur at a same given moment (Craske et al. 2017). Thus, our study shows that there are no crosssectional additive effects of other anxiety disorders increasing nitro-oxidative pathways in BD and MDD.

Another finding is that the nitro-oxidative pathways measured here are modulated by sex, nicotine dependence, and years of education. Thus, males show higher LOOH, AOPP, and uric acid levels, but lower catalase and HDL-cholesterol levels. These findings corroborate those of previous research reporting that plasma peroxides and ROS production are higher in males than females (Maes et al. 2010; Katalinic et al. 2005). There are now some studies showing that smoking may decrease PON1 activities (Haj Mouhamed et al. 2012; Souza-Nogueira et al. 2016) and HDLcholesterol levels (He et al. 2013; Nunes et al. 2015; Bortolasci et al. 2014b). There is also a significant effect of smoking and tobacco use disorder on the nitro-oxidative pathways with increased SOD and LOOH levels, but lower HDLcholesterol and PON1 activities. van der Vaart et al. (2004) and Donohue (2006) found strong effects of smoking on O\&NS pathways. Based on our results, we may conclude that the effects of smoking on lipid-associated antioxidants and lipid peroxidation may contribute to the pathophysiological underpinnings of GAD. Previously, it has been reviewed that smoking and nicotine dependence may increase the risk of GAD (Moylan et al. 2015) and that there is a significant comorbidity between GAD and TUD (Fluharty et al. 2016). Finally, also education has a very modest effect on nitrooxidative pathways. Thus, years of education was significantly associated with SOD1 (inversely), CAT (positively), and MDA (inversely), suggesting that years of education may protect against ROS generation and lipid peroxidation with aldehyde production. It is probably that the effects of education may be explained by a healthier lifestyle in more educated individuals improving antioxidant defenses through better nutrition and exercise (Lobo et al. 2010; Moylan et al. 2013).

The findings of our study should be interpreted with regard to limitations. Firstly, this study has a cross-sectional design 
and therefore, no firm causal inferences can be established. Secondly, the number of patients with social phobia, simple phobia, and panic disorder was too small to compute effects of each anxiety disorder. Thirdly, future studies should examine other O\&NS biomarkers in GAD including but not limited to MPO, xanthine oxidase, and the protective IgM-mediated natural autoimmune responses to oxidatively formed neoepitopes (Roomruangwong et al. 2018).

In conclusion, this study shows that aberrations in nitrooxidative pathways are highly significantly associated with GAD. GAD is characterized by lowered PON1 activity and HDL-cholesterol levels, which contribute to elevated nitrooxidative stress with consequent lipid peroxidation. Nevertheless, aldehyde production and protein oxidation are not fully expressed in GAD despite highly enhanced nitro-oxidative stress. This may be explained by increased uric acid levels in GAD which are known to attenuate hydroxyl radical and peroxynitrite production. The results suggests that nitro-oxidative biomarkers (especially SOD1, PON1, and uric acid) may participate in the pathophysiology of GAD and that lowered HDL-cholesterol and PON1 activities and increased nitro-oxidative stress are novel drug targets in GAD. Furthermore, we found cumulative effects of mood and anxiety disorders on nitrooxidative pathways with more activated pathways in the comorbid GAD and MDD phenotype, in comparison with GAD or MDD alone. Our results contribute to the neurobiology-informed classification of psychiatric disorders, especially under the Research Domain Criteria model (Cuthbert and Insel 2010).

Acknowledgements The authors wish to thank the Centre of Approach and Treatment for Smokers, Psychiatric Unit at UEL, Clinical Laboratory of the University Hospital and Laboratory of Research and Graduate College Hospital (LPG), Brazil.

Author Contributions All authors contributed to the writing up of the paper. The work was designed by SOVN, MM, DSB, EGM, and HOV. Data were collected by SOVN and HOV. Laboratory analyses were conducted by KLB, NRM, EGM, and DSB. Statistics were performed by MM. AFC and DSS revised the manuscript and provided relevant intellectual content. All authors revised and approved the final draft.

Funding This study was supported by Health Sciences Postgraduate Program at Londrina State University, Parana, Brazil (UEL), and Ministry for Science and Technology of Brazil (CNPq). CNPq number 470344/2013-0 and CNPq number 465928/2014-5. MM is supported by a CNPq-PVE fellowship and the Health Sciences Graduate Program fellowship, State University of Londrina.

\section{Compliance with Ethical Standards}

All participants gave written informed consent to take part in the current study, whose experimental procedures were previously approved by the Research Ethics Committee at UEL (protocol number: CAAE 34935814.2.0000.5231)

\section{References}

American Psychiatric Association (2000) Diagnostic and statistical manual of mental disorders, 4th ed., Text Revision edn. Author, Washington DC

Anderson ME (1985) Determination of glutathione disulfide in biological samples. Methods Enzymol 113:548-555

Andreazza AC, Kauer-Sant'anna M, Frey BN, Bond DJ, Kapczinski F, Young LT, Yatham LN (2008) Oxidative stress markers in bipolar disorder: a meta-analysis. J Affect Disord 111(2-3):135-144

Annigeri B, Raman R, Appaji R (2011) Obsessive compulsive disorder with bipolar mood disorder: a rare comorbidity in India. Ind $\mathrm{J}$ Psychol Med 33:83-85

Arnhold J, Flemmig J (2010) Human myeloperoxidase in innate and acquired immunity. Arch Biochem Biophys 500(1):92-106

Atasoy H, Güleç-Yilmaz S, Ergen A, Görmüș U, Küçükhüseyin Ö, Dalan B, Ol KK, Ögüt DB, Güleç H, Çetin B, Timirci-Kahraman Ö, Örmeci B, Uçunoğlu N, Gultekin GI, İsbir T (2015) Paraoxonase1 192 (PON1 192) gene polymorphism and serum paraoxonase activity in panic disorder patients. In Vivo 29(1):51-54

Atmaca M, Tezcan E, Kuloglu M, Ustundag B, Tunckol H (2004) Antioxidant enzyme and malondialdehyde values in social phobia before and after citalopram treatment. Eur Arch Psychiatry Clin Neurosci 254(4):231-235

Bartoli F, Crocamo C, Mazza MG, Clerici M, Carrà G (2016) Uric acid levels in subjects with bipolar disorder: a comparative meta-analysis. J Psychiatr Res 81:133-139

Bastos AS, Loureiro AP, de Oliveira TF, Corbi SC, Caminaga RM, Junior CR, Orrico SR (2012) Quantitation of malondialdehyde in gingival crevicular fluid by a high-performance liquid chromatographybased method. Anal Biochem 423:141-146

Benjamini Y, Hochberg Y (1995) Controlling the false discovery rate: a practical and powerful approach to multiple testing. J Royal Stat Soc Series B (Methodological) 57:289-300

Bilici M, Efe H, Köroğlu MA, Uydu HA, Bekaroğlu M, Değer O (2001) Antioxidative enzyme activities and lipid peroxidation in major depression: alterations by antidepressant treatments. J Affect Disord 64(1):43-51

Billecke SS, Teiber JF (2011) Pitfalls in the assessment of PON1 status in clinical populations. Fertil Steril 95(8):e63-author reply e64

Black CN, Bot M, Scheffer PG, Snieder H, Penninx BWJH (2018) Uric acid in major depressive and anxiety disorders. J Affect Disord 225: 684-690

Bortolasci CC, Vargas HO, Souza-Nogueira A, Barbosa DS, Moreira EG, Nunes SO, Berk M, Dodd S, Maes M (2014a) Lowered plasma paraoxonase (PON)1 activity is a trait marker of major depression and PON1 Q192R gene polymorphism-smoking interactions differentially predict the odds of major depression and bipolar disorder. $\mathrm{J}$ Affect Disord 159:23-30

Bortolasci CC, Vargas HO, Souza-Nogueira A, Gastaldello Moreira E, Vargas Nunes SO, Berk M, Dodd S, Barbosa DS, Maes M (2014b) Paraoxonase (PON)1 Q192R functional genotypes and PON1 Q192R genotype by smoking interactions are risk factors for the metabolic syndrome, but not overweight or obesity. Redox Rep 19(6):232-241

Brown NC, Andreazza AC, Young LT (2014) An updated meta-analysis of oxidative stress markers in bipolar disorder. Psychiatry Res 218(1-2):61-68

Bulut M, Selek S, Bez Y, Karababa IF, Kaya MC, Gunes M, Emhan A, Aksoy N, Sir A (2013) Reduced PON1 enzymatic activity and increased lipid hydroperoxide levels that point out oxidative stress in generalized anxiety disorder. J Affect Disord 150(3):829-833

Carroll D, Phillips AC, Thomas GN, Gale CR, Deary I, Batty GD (2009) Generalized anxiety disorder is associated with metabolic syndrome in the Vietnam experience study. Biol Psychiatry 66(1):91-93 
Cengiz M, Bayoglu B, Alansal NO, Cengiz S, Dirican A, Kocabasoglu N (2015) Pro198Leu polymorphism in the oxidative stress gene, glutathione peroxidase-1, is associated with a gender-specific risk for panic disorder. Int J Psychiatry Clin Pract 19(3):201-207

Costa LG, Cole TB, Furlong CE (2005) Paraoxonase (PON1): from toxicology to cardiovascular medicine. Acta Biomed 76(Suppl 2):50-57

Craske MG, Stein MB, Eley TC, Milad MR, Holmes A, Rapee RM, Wittchen HU (2017) Anxiety disorders. Nat Rev Dis Primers 3: 17024

Culpepper L (2008) Primary care management of patients with cooccurring disorders. CNS Spectr 13(4 Suppl 6):13-15

Cuthbert BN, Insel TR (2010) Toward new approaches to psychotic disorders: the NIMH Research Domain Criteria project. Schizophr Bull 36(6):1061-1062

de Melo LGP, Nunes SOV, Anderson G, Vargas HO, Barbosa DS, Galecki P, Carvalho AF, Maes M (2017) Shared metabolic and immune-inflammatory, oxidative and nitrosative stress pathways in the metabolic syndrome and mood disorders. Prog NeuroPsychopharmacol Biol Psychiatry 78:34-50

Del-Ben CM, Vilela JAA, Crippa JAS, Hallak JEC, Labate CM et al (2001) Confiabilidade da "Entrevista Clínica Estruturada para o DSM-IV - Versão Clínica" traduzida para o português. Rev Bras Psiquiatr 23:156-159

Donohue JF (2006) Ageing, smoking and oxidative stress. Thorax 61(6): 461-462

Efrat M, Aviram M (2010) Paraoxonase 1 interactions with HDL, antioxidants and macrophages regulate atherogenesis - a protective role for HDL phospholipids. Adv Exp Med Biol 660:153-166

Emhan A, Selek S, Bayazıt H, Fatih Karababa İ, Katı M, Aksoy N (2015) Evaluation of oxidative and antioxidative parameters in generalized anxiety disorder. Psychiatry Res 230(3):806-810

Ercan AC, Bahceci B, Polat S, Cenker OC, Bahceci I, Koroglu A, Sahin $\mathrm{K}$, Hocaoglu C (2017) Oxidative status and prolidase activities in generalized anxiety disorder. Asian J Psychiatr 25:118-122

Fava M, Rankin MA, Wright EC, Alpert JE, Nierenberg AA, Pava J, Rosenbaum JF (2000) Anxiety disorders in major depression. Compr Psychiatry 41(2):97-102

Fluharty ME, Attwood AS, Munafò MR (2016) Anxiety sensitivity and trait anxiety are associated with response to $7.5 \%$ carbon dioxide challenge. J Psychopharmacol 30(2):182-187

Fukai T, Ushio-Fukai M (2011) Superoxide dismutases: role in redox signaling, vascular function, and diseases. Antioxid Redox Signal 15(6):1583-1606

Gałecki P, Gałecka E, Maes M, Chamielec M, Orzechowska A, Bobińska K, Lewiński A, Szemraj J (2012) The expression of genes encoding for COX-2, MPO, iNOS, and SPLA2-IIA in patients with recurrent depressive disorder. J Affect Disord 138(3):360-366

Gersch C, Palii SP, Imaram W, Kim KM, Karumanchi SA, Angerhofer A, Johnson RJ, Henderson GN (2009) Reactions of peroxynitrite with uric acid: formation of reactive intermediates, alkylated products and triuret, and in vivo production of triuret under conditions of oxidative stress. Nucleosides Nucleotides Nucleic Acids 28(2): 118-149

Girotti AW (1998) Lipid hydroperoxide generation, turnover, and effector action in biological systems. J Lipid Res 39(8):1529-1542

Gomes C, Martinho FC, Barbosa DS, Antunes LS, Póvoa HCC, Baltus THL, Morelli NR, Vargas HO, Nunes SOV, Anderson G, Maes M (2017) Increased root canal endotoxin levels are associated with chronic apical periodontitis, increased oxidative and nitrosative stress, major depression, severity of depression, and a lowered quality of life. Mol Neurobiol Apr 28. Doi:https://doi.org/10.1007/ s12035-017-0545-Z

Gonzalez FB, Llesuy S, Boveris A (1991) Hydroperoxide-initiated chemiluminescence: an assay for oxidative stress in biopsies of heart, liver, and muscle. Free Radic Biol Med 10:93-100
Gugliucci A, Menini T (2015) Paraoxonase 1 and HDL maturation. Clin Chim Acta 439:5-13

Guimarães PM, Scavuzzi BM, Stadtlober NP, Franchi Santos LFDR, Lozovoy MAB, Iriyoda TMV, Costa NT, Reiche EMV, Maes M, Dichi I, Simão ANC (2017) Cytokines in systemic lupus erythematosus: far beyond Th1/Th2 dualism lupus: cytokine profiles. Immunol Cell Biol 95(9):824-831

Gul IG, Karlidag R, Cumurcu BE, Turkoz Y, Kartalci S, Ozcan AC, Erdemli ME (2013) The effect of agoraphobia on oxidative stress in panic disorder. Psychiatry Investig 10(4):317-325

Hagan KA, Wu T, Rimm EB, Eliassen AH, Okereke OI (2015) Phobic anxiety and plasma levels of global oxidative stress in women. Eur J Psychiatry 29(1):7-20

Haider S, Naqvi F, Batool Z, Tabassum S, Sadir S, Liaquat L, Naqvi F, Zuberi NA, Shakeel H, Perveen T (2015) Pretreatment with curcumin attenuates anxiety while strengthens memory performance after one short stress experience in male rats. Brain Res Bull 115:1-8

Haj Mouhamed D, Ezzaher A, Mechri A, Neffati F, Omezzine A, Bouslama A, Gaha L, Douki W, Najjar MF (2012) Effect of cigarette smoking on paraoxonase 1 activity according to PON1 L55M and PON1 Q192R gene polymorphisms. Environ Health Prev Med 17(4):316-321

Hamilton M (1959) The assessment of anxiety states by rating. Br J Med Psychol 32(1):50-55

Hamilton M (1960) A rating scale for depression. J Neurol Neurosurg Psychiatry 23:56-62

Hanasand M, Omdal R, Norheim KB, Gransson LG, Brede C, Jonsson G (2012) Improved detection of advanced oxidation protein products in plasma. Clin Chim Acta 413:901-906

Harris ED (1992) Copper as a cofactor and regulator of copper, zinc superoxide dismutase. J Nutr 122(3 Suppl):636-640

Hassan W, Gomes Vde C, Pinton S, Batista Teixeira da Rocha J, Landeira-Fernandez J $(2013,1512)$ Association between oxidative stress and contextual fear conditioning in Carioca high- and lowconditioned freezing rats. Brain Res:60-67

Hassan W, Silva CE, Mohammadzai IU, da Rocha JB (2014) Association of oxidative stress to the genesis of anxiety: implications for possible therapeutic interventions. Curr Neuropharmacol 12(2):120-139

Hawke LD, Provencher MD, Parikh SV, Zagorski B (2013) Comorbid anxiety disorders in Canadians with bipolar disorder: clinical characteristics and service use. Can J Psychiatr 58(7):393-401

Hayyan M, Hashim MA, AlNashef IM (2016) Superoxide ion: generation and chemical implications. Chem Rev 116(5):3029-3085

He BM, Zhao SP, Peng ZY (2013) Effects of cigarette smoking on HDL quantity and function: implications for atherosclerosis. J Cell Biochem 114(11):2431-2436

Henrique IFS, De Micheli D, RBd L, LAd L, Formigoni MLOS (2004) Validação da versão brasileira do teste de triagem do envolvimento com álcool, cigarro e outras substâncias (ASSIST). Rev Assoc Med Bras 5:199-206

Hettema JM (2008) The nosologic relationship between generalized anxiety disorder and major depression. Depress Anxiety 25(4):300-316

Hovatta I, Tennant RS, Helton R, Marr RA, Singer O, Redwine JM, Ellison JA, Schadt EE, Verma IM, Lockhart DJ, Barlow C (2005) Glyoxalase 1 and glutathione reductase 1 regulate anxiety in mice. Nature 438(7068):662-666

Huang Y, Wu Z, Riwanto M, Gao S, Levison BS, Gu X, Fu X, Wagner MA, Besler C, Gerstenecker G, Zhang R, Li XM, DiDonato AJ, Gogonea V, Tang WH, Smith JD, Plow EF, Fox PL, Shih DM, Lusis AJ, Fisher EA, DiDonato JA, Landmesser U, Hazen SL (2013) Myeloperoxidase, paraoxonase-1, and HDL form a functional ternary complex. J Clin Invest 123(9):3815-3828

Ishigami N, Isoda K, Adachi T, Niida T, Kujiraoka T, Hakuno D, Kondo H, Kusuhara M, Ohsuzu F (2011) Deficiency of CuZn superoxide dismutase promotes inflammation and alters medial structure following vascular injury. J Atheroscler Thromb 18(11):1009-1017 
Jarvik GP, Rozek LS, Brophy VH, Hatsukami TS, Richter RJ, Schellenberg GD, Furlong CE (2000) Paraoxonase (PON1) phenotype is a better predictor of vascular disease than is PON1 192 or PON1 55 genotype. Arterioscler Thromb Vasc Biol 20:2441-2447

Katalinic V, Modun D, Music I, Boban M (2005) Gender differences in antioxidant capacity of rat tissues determined by $2,2^{\prime}$-azinobis (3ethylbenzothiazoline 6-sulfonate; ABTS) and ferric reducing antioxidant power (FRAP) assays. Comp Biochem Physiol C Toxicol Pharmacol 140(1):47-52

Kaya MC, Bez Y, Karababa IF, Emhan A, Aksoy N, Bulut M, Gunes M, Atli A, Selek S (2013) Decreased serum sulphydryl levels as a sign of increased oxidative stress in generalized anxiety disorder. Psychiatry Investig 10(3):281-285

Khanzode SD, Dakhale GN, Khanzode SS, Saoji A, Palasodkar R (2003) Oxidative damage and major depression: the potential antioxidant action of selective serotonin re-uptake inhibitors. Redox Rep 8(6): 365-370

Kubera M, Lin AH, Kenis G, Bosmans E, van Bockstaele D, Maes M (2001) Anti-inflammatory effects of antidepressants through suppression of the interferon-gamma/interleukin-10 production ratio. J Clin Psychopharmacol 21(2):199-206

Kumar A, Chanana P (2017) Role of nitric oxide in stress-induced anxiety: from pathophysiology to therapeutic target. Vitam Horm 103: $147-167$

Kuppusamy P, Zweier JL (1989) Characterization of free radical generation by xanthine oxidase. Evidence for hydroxyl radical generation. J Biol Chem 264(17):9880-9884

Liu T, Zhong S, Liao X, Chen J, He T, Lai S, Jia Y (2015) A metaanalysis of oxidative stress markers in depression. PLoS One 10(10): 0138904

Lobo V, Patil A, Phatak A, Chandra N (2010) Free radicals, antioxidants and functional foods: impact on human health. Pharmacogn Rev 4(8):118-126

Mackness M, Mackness B (2015) Human paraoxonase-1 (PON1): gene structure and expression, promiscuous activities and multiple physiological roles. Gene 567(1):12-21

Maes M (2008) The cytokine hypothesis of depression: inflammation, oxidative \& nitrosative stress (IO\&NS) and leaky gut as new targets for adjunctive treatments in depression. Neuro Endocrinol Lett 29(3):287-291

Maes M, Carvalho AF (2018) The compensatory immune-regulatory reflex system (CIRS) in depression and bipolar disorder. Mol Neurobiol. https://doi.org/10.1007/s12035-018-1016-x

Maes M, Delanghe J, Meltzer HY, Scharpé S, D’Hondt P, Cosyns P (1994a) Lower degree of esterification of serum cholesterol in depression: relevance for depression and suicide research. Acta Psychiatr Scand 90(4):252-258

Maes M, Meltzer HY, Cosyns P, Schotte C (1994b) Evidence for the existence of major depression with and without anxiety features. Psychopathology 27(1-2):1-13

Maes M, Smith R, Christophe A, Cosyns P, Desnyder R, Meltzer H (1996) Fatty acid composition in major depression: decreased omega 3 fractions in cholesteryl esters and increased C20: 4 omega 6/C20:5 omega 3 ratio in cholesteryl esters and phospholipids. J Affect Disord 38(1):35-46

Maes M, Smith R, Christophe A, Vandoolaeghe E, Van Gastel A, Neels H, Demedts P, Wauters A, Meltzer HY (1997) Lower serum high-density lipoprotein cholesterol (HDL-C) in major depression and in depressed men with serious suicidal attempts: relationship with immuneinflammatory markers. Acta Psychiatr Scand 95(3):212-221

Maes M, Song C, Lin A, DeJong R, Van Gastel A, Kenis G, Bosmans E, DeMeester I, Neels H, Janca A, Scharpe S, Smith RS (1998) Immune and clinical correlates of psychological stress-induced production of interferon- $\gamma$ and interleukin-10 in humans. Cytokines, Stress and Immunity; Editors: Plotnikoff NP, Faith RE, Murgo AJ, Good RA; pp. 39-50
Maes M, Christophe A, Delanghe J, Altamura C, Neels H, Meltzer HY (1999a) Lowered omega3 polyunsaturated fatty acids in serum phospholipids and cholesteryl esters of depressed patients. Psychiatry Res 85(3):275-291

Maes M, Song C, Lin AH, Bonaccorso S, Kenis G, De Jongh R, Bosmans E, Scharpé S (1999b) Negative immunoregulatory effects of antidepressants: inhibition of interferon-gamma and stimulation of interleukin-10 secretion. Neuropsychopharmacology 20(4):370-379

Maes M, De Vos N, Pioli R, Demedts P, Wauters A, Neels H, Christophe A (2000) Lower serum vitamin E concentrations in major depression. Another marker of lowered antioxidant defenses in that illness. J Affect Disord 58(3):241-246

Maes M, Mihaylova I, Kubera M, Uytterhoeven M, Vrydags N, Bosmans E (2009) Lower plasma coenzyme Q10 in depression: a marker for treatment resistance and chronic fatigue in depression and a risk factor to cardiovascular disorder in that illness. Neuro Endocrinol Lett 30(4):462-469

Maes M, Mihaylova I, Kubera M, Uytterhoeven M, Vrydags N, Bosmans E (2010) Increased plasma peroxides and serum oxidized low density lipoprotein antibodies in major depression: markers that further explain the higher incidence of neurodegeneration and coronary artery disease. J Affect Disord 125(1-3):287-294

Maes M, Galecki P, Chang YS, Berk M (2011a) A review on the oxidative and nitrosative stress (O\&NS) pathways in major depression and their possible contribution to the (neuro)degenerative processes in that illness. Prog Neuro-Psychopharmacol Biol Psychiatry 35(3): 676-692

Maes M, Mihaylova I, Kubera M, Leunis JC, Geffard M (2011b) IgMmediated autoimmune responses directed against multiple neoepitopes in depression: new pathways that underpin the inflammatory and neuroprogressive pathophysiology. J Affect Disord 135(1-3):414-418

Maes M, Ruckoanich P, Chang YS, Mahanonda N, Berk M (2011c) Multiple aberrations in shared inflammatory and oxidative \& nitrosative stress (IO\&NS) pathways explain the co-association of depression and cardiovascular disorder (CVD), and the increased risk for CVD and due mortality in depressed patients. Prog NeuroPsychopharmacol Biol Psychiatry 35(3):769-783

Marikovsky M, Ziv V, Nevo N, Harris-Cerruti C, Mahler O (2003) Cu/Zn superoxide dismutase plays important role in immune response. $\mathrm{J}$ Immunol 170(6):2993-3001

Marklund S, Marklund G (1974) Involvement of the superoxide dismutase anion radical in the autoxidation of pyrogallol and a convenient assay for superoxide dismutase. Eur J Biochem 47:469-471

Martens EJ, de Jonge P, Na B, Cohen BE, Lett H, Whooley MA (2010) Scared to death? Generalized anxiety disorder and cardiovascular events in patients with stable coronary heart disease: the Heart and Soul Study. Arch Gen Psychiatry 67(7):750-758

Mazereeuw G, Herrmann N, Andreazza AC, Khan MM, Lanctôt KL (2015) A meta-analysis of lipid peroxidation markers in major depression. Neuropsychiatr Dis Treat 11:2479-2491

McCord JM, Edeas MA (2005) SOD, oxidative stress and human pathologies: a brief history and a future vision. Biomed Pharmacother 59(4):139-142

Mennin DS, Heimberg RG, Fresco DM, Ritter MR (2008) Is generalized anxiety disorder an anxiety or mood disorder? Considering multiple factors as we ponder the fate of GAD. Depress Anxiety 25(4):289-299

Merikangas KR, Akiskal HS, Angst J, Greenberg PE, Hirschfeld RM, Petukhova M, Kessler RC (2007) Lifetime and 12-month prevalence of bipolar spectrum disorder in the National Comorbidity Survey replication. Arch Gen Psychiatry 64(5):543-552

Miao L, St Clair DK (2009) Regulation of superoxide dismutase genes: implications in disease. Free Radic Biol Med 47(4):344-356 
Michopoulos V, Powers A, Gillespie CF, Ressler KJ, Jovanovic T (2017) Inflammation in fear- and anxiety-based disorders: PTSD, GAD, and beyond. Neuropsychopharmacology 42(1):254-270

Moraes JB, Maes M, Roomruangwong C, Bonifacio KL, Barbosa DS, Vargas HO, Anderson G, Kubera M, Carvalho AF, Nunes SOV. In major affective disorders, early life trauma predict increased nitrooxidative stress, lipid peroxidation and protein oxidation and recurrence of major affective disorders, suicidal behaviors and a lowered quality of life. Metab Brain Dis. 2018. https://doi.org/10.1007/ s11011-018-0209-3

Moreira EG, Correia DG, Bonifácio KL, Moraes JB, Cavicchioli FL, Nunes CS, Nunes SOV, Vargas HO, Barbosa DS, Maes M (2017) Lowered PON1 activities are strongly associated with depression and bipolar disorder, recurrence of (hypo)mania and depression, increased disability and lowered quality of life. World J Biol Psychiatry 30:1-13

Morris G, Berk M, Klein H, Walder K, Galecki P, Maes M (2017 Aug) Nitrosative stress, hypernitrosylation, and autoimmune responses to nitrosylated proteins: new pathways in neuroprogressive disorders including depression and chronic fatigue syndrome. Mol Neurobiol 54(6):4271-4291

Moylan S, Eyre HA, Maes M, Baune BT, Jacka FN, Berk M (2013) Exercising the worry away: how inflammation, oxidative and nitrogen stress mediates the beneficial effect of physical activity on anxiety disorder symptoms and behaviours. Neurosci Biobehav Rev 37(4):573-584

Moylan S, Berk M, Dean OM, Samuni Y, Williams LJ, O’Neil A, Hayley AC, Pasco JA, Anderson G, Jacka FN, Maes M (2014) Oxidative \& nitrosative stress in depression: why so much stress? Neurosci Biobehav Rev 45:46-62

Moylan S, Gustavson K, Øverland S, Karevold EB, Jacka FN, Pasco JA, Berk M (2015) The impact of maternal smoking during pregnancy on depressive and anxiety behaviors in children: the Norwegian Mother and Child Cohort Study. BMC Med $13: 24$

Nabavi B, Mitchell AJ, Nutt D (2015) A lifetime prevalence of comorbidity between bipolar affective disorder and anxiety disorders: a meta-analysis of 52 interview-based studies of psychiatric population. EBioMedicine 2:1405-1419

Navarro-Gonzalvez JA, Garcia-Benayas C, Arenas J (1998) Semiautomated measurement of nitrate in biological fluids. Clin Chem 44:679-681

Nunes SO, Vargas HO, Prado E, Barbosa DS, de Melo LP, Moylan S, Dodd S, Berk M (2013) The shared role of oxidative stress and inflammation in major depressive disorder and nicotine dependence. Neurosci Biobehav Rev 37(8):1336-1345

Nunes SO, Piccoli de Melo LG, Pizzo de Castro MR, Barbosa DS, Vargas HO, Berk M, Maes M (2015) Atherogenic index of plasma and atherogenic coefficient are increased in major depression and bipolar disorder, especially when comorbid with tobacco use disorder. J Affect Disord 172:55-62

Otto MW, Perlman CA, Wernicke R, Reese HE, Bauer MS, Pollack MH (2004) Posttraumatic stress disorder in patients with bipolar disorder: a review of prevalence, correlates, and treatment strategies. Bipolar Disord 6:470-479

Ozcan ME, Gulec M, Ozerol E, Polat R, Akyol O (2004) Antioxidant enzyme activities and oxidative stress in affective disorders. Int Clin Psychopharmacol 19(2):89-95

Pacher P, Beckman JS, Liaudet L (2007) Nitric oxide and peroxynitrite in health and disease. Physiol Rev 87(1):315-424

Panis C, Herrera ACSA, Victorino VJ, Campos FC, Freitas LF, De Rossi T, Colado Simao AN, Cecchini AL, Cecchini R (2012) Oxidative stress and hematological profiles of advanced breast cancer patients subjected to paclitaxel or doxorubicin chemotherapy. Breast Cancer Res Treat 133:89-97
Peet M, Murphy B, Shay J, Horrobin D (1998) Depletion of omega-3 fatty acid levels in red blood cell membranes of depressive patients. Biol Psychiatry 43(5):315-319

Peng D, Jiang K (2015) Comorbid bipolar disorder and obsessivecompulsive disorder. Shanghai Arch Psychiatry 27:246-248

Rammal H, Bouayed J, Younos C, Soulimani R (2008) Evidence that oxidative stress is linked to anxiety-related behaviour in mice. Brain Behav Immun 22(8):1156-1159

Regoli F, Winston GW (1999) Quantification of total oxidant scavenging capacity of antioxidants for peroxynitrite, peroxyl radicals, and hydroxyl radicals. Toxicol Appl Pharmacol 156(2):96-105

Richter RJ, Jarvik GP, Furlong CE (2009) Paraoxonase 1 (PON1) status and substrate hydrolysis. Toxicol Appl Pharmacol 235(1):1-9

Rojo AI, Salinas M, Martín D, Perona R, Cuadrado A (2004) Regulation of $\mathrm{Cu} / \mathrm{Zn}$-superoxide dismutase expression via the phosphatidylinositol 3 kinase/Akt pathway and nuclear factor-kappaB. J Neurosci 24(33):7324-7334

Roomruangwong C, Barbosa DS, Matsumoto AK, Nogueira AS, Kanchanatawan B, Sirivichayakul S, Carvalho AF, Duleu S, Geffard M, Moreira EG, Maes M (2017) Activated neurooxidative and neuro-nitrosative pathways at the end of term are associated with inflammation and physio-somatic and depression symptoms, while predicting outcome characteristics in mother and baby. J Affect Disord 223:49-58

Roomruangwong C, Barbosa DS, de Farias CC, Matsumoto AK, Baltus THL, Morelli NR, Kanchanatawan B, Duleu S, Geffard M, Maes M (2018) Natural regulatory IgM-mediated autoimmune responses directed against malondialdehyde regulate oxidative and nitrosative pathways and coupled with IgM responses to nitroso adducts attenuate depressive and physiosomatic symptoms at the end of term pregnancy. Psychiatry Clin Neurosci 72(2):116-130

Saran M, Michel C, Stettmaier K, Bors W (2000) Arguments against the significance of the Fenton reaction contributing to signal pathways under in vivo conditions. Free Radic Res 33(5):567-579

Sautin YY, Johnson RJ (2008) Uric acid: the oxidant-antioxidant paradox. Nucleosides Nucleotides Nucleic Acids 27(6):608-619

Sobczak S, Honig A, Christophe A, Maes M, Helsdingen RW, De Vriese SA, Riedel WJ (2004) Lower high-density lipoprotein cholesterol and increased omega- 6 polyunsaturated fatty acids in first-degree relatives of bipolar patients. Psychol Med 34(1):103-112

Soltani Z, Rasheed K, Kapusta DR, Reisin E (2013) Potential role of uric acid in metabolic syndrome, hypertension, kidney injury, and cardiovascular diseases: is it time for reappraisal? Curr Hypertens Rep 15(3):175-181

Souza-Nogueira A, Camargo AE, Remondi FA, Paoliello MM, Richter RJ, Furlong CE, Barbosa DS, Maes M, Moreira EG (2016) Paraoxonase 1 (PON1) Q192R genotypes and their interaction with smoking strongly increase atherogenicity and the Framingham risk score. Arch Endocrinol Metab 60(5):426-435

Sowa-Kućma M, Styczeń K, Siwek M, Misztak P, Nowak RJ, Dudek D, Rybakowski JK, Nowak G, Maes M (2017) Lipid peroxidation and immune biomarkers are associated with major depression and its phenotypes, including treatment-resistant depression and melancholia. Neurotox Res. Nov 4. https://doi.org/10.1007/s12640-0179835-5

Sowa-Kućma M, Styczeń K, Siwek M, Misztak P, Nowak RJ, Dudek D, Rybakowski JK, Nowak G, Maes M (2018) Are there differences in lipid peroxidation and immune biomarkers between major depression and bipolar disorder: effects of melancholia, atypical depression, severity of illness, episode number, suicidal ideation and prior suicide attempts. Prog Neuro-Psychopharmacol Biol Psychiatry 81: 372-383

Stoyanov DS (2017) Key developments in translational neuroscience: an update. Balkan Med J 34(6):485-486

Terrazzano G, Rubino V, Damiano S, Sasso A, Petrozziello T, Ucci V, Palatucci AT, Giovazzino A, Santillo M, De Felice B, Garbi C, 
Mondola P, Ruggiero G (2014) T cell activation induces CuZn superoxide dismutase (SOD)-1 intracellular re-localization, production and secretion. Biochim Biophys Acta 1843(2):265-274

Tietze F (1969) Enzymic method for quantitative determination of nanogram amounts of total and oxidized glutathione: applications to mammalian blood and other tissues. Anal Biochem 27(3):502-522

Tsuboi H, Tatsumi A, Yamamoto K, Kobayashi F, Shimoi K, Kinae N (2006) Possible connections among job stress, depressive symptoms, lipid modulation and antioxidants. J Affect Disord 91(1):63-70

Tully PJ, Cosh S (2013) Generalized anxiety disorder prevalence and comorbidity with depression in coronary heart disease: a meta analysis. J Health Psychol 18(12):1601-1616

Valko M, Leibfritz D, Moncol J, Cronin MT, Mazur M, Telser J (2007) Free radicals and antioxidants in normal physiological functions and human disease. Int J Biochem Cell Biol 39(1):44-84

van der Vaart H, Postma DS, Timens W, ten Hacken NH (2004) Acute effects of cigarette smoke on inflammation and oxidative stress: a review. Thorax 59(8):713-721

Vilela JA, Crippa JA, Del-Ben CM, Loureiro SR (2005) Reliability and validity of a Portuguese version of the Young Mania Rating Scale. Braz J Med Biol Res 38(9):1429-1439

Watson AD, Berliner JA, Hama SY, La Du BN, Faull KF, Fogelman AM, Navab M (1995) Protective effect of sity lipoprotein associated paraoxonase. Inhibition of the biological activity of minimally oxidized low density lipoprotein. J Clin Invest 96(6):2882-2891
Wen S, Cheng M, Wang H, Yue J, Wang H, Li G, Zheng L, Zhong Z, Peng F (2012) Serum uric acid levels and the clinical characteristics of depression. Clin Biochem 45(1-2):49-53

WHO ASSIST Working Group (2002) The Alcohol, Smoking and Substance Involvement Screening Test (ASSIST): development, reliability and feasibility. Addiction 97:1183-1194

Witko-Sarsat V, Friedlander M, Capeillère-Blandin C, Nguyen-Khoa T, Nguyen AT, Zingraff J, Jungers P, Descamps-Latscha B (1996) Advanced oxidation protein products as a novel marker of oxidative stress in uremia. Kidney Int 49(5):1304-1313

Wium-Andersen MK, Kobylecki CJ, Afzal S, Nordestgaard BG (2017) Association between the antioxidant uric acid and depression and antidepressant medication use in 96989 individuals. Acta Psychiatr Scand 136(4):424-433

Xing J, Yu Y, Rando TA (2002) The modulation of cellular susceptibility to oxidative stress: protective and destructive actions of $\mathrm{Cu}, \mathrm{Zn}$-superoxide dismutase. Neurobiol Dis 10(3):234-246

Zelko IN, Mariani TJ, Folz RJ (2002 Aug 1) Superoxide dismutase multigene family: a comparison of the CuZn-SOD (SOD1), MnSOD (SOD2), and EC-SOD (SOD3) gene structures, evolution, and expression. Free Radic Biol Med 33(3):337-349

Zhou Y, Cao Z, Yang M, Xi X, Guo Y, Fang M, Cheng L, Du Y (2017) Comorbid generalized anxiety disorder and its association with quality of life in patients with major depressive disorder. Sci Rep 7:40511 